\title{
Highly pressurized partially miscible liquid-liquid flow in a micro-T-junction. I. Experimental observations
}

\author{
Ning Qin, John Z. Wen, and Carolyn L. Ren* \\ Department of Mechanical and Mechatronics Engineering, University of Waterloo, Waterloo, Ontario, Canada N2L3G1
}

(Received 12 October 2016; published 24 April 2017)

\begin{abstract}
This is the first part of a two-part study on a partially miscible liquid-liquid flow (liquid carbon dioxide and deionized water) which is highly pressurized and confined in a microfluidic T-junction. Our main focuses are to understand the flow regimes as a result of varying flow conditions and investigate the characteristics of drop flow distinct from coflow, with a capillary number, $\mathrm{Ca}_{c}$, that is calculated based on the continuous liquid, ranging from $10^{-3}$ to $10^{-2}\left(10^{-4}\right.$ for coflow). Here in part I, we present our experimental observation of drop formation cycle by tracking drop length, spacing, frequency, and after-generation speed using high-speed video and image analysis. The drop flow is chronologically composed of a stagnating and filling stage, an elongating and squeezing stage, and a truncating stage. The common "necking" time during the elongating and squeezing stage (with $\mathrm{Ca}_{c} \sim 10^{-3}$ ) for the truncation of the dispersed liquid stream is extended, and the truncation point is subsequently shifted downstream from the T-junction corner. This temporal postponement effect modifies the scaling function reported in the literature for droplet formation with two immiscible fluids. Our experimental measurements also demonstrate the drop speed immediately following their generations can be approximated by the mean velocity from averaging the total flow rate over the channel cross section. Further justifications of the quantitative analysis by considering the mass transfer at the interface of the two partially miscible fluids are provided in part II.
\end{abstract}

DOI: 10.1103/PhysRevE.95.043110

\section{INTRODUCTION}

Two-phase flows (specifically, liquid-liquid and gas-liquid) within confined microscale planar geometries such as crossflowing junctions, flow focusing channels, and coflowing devices are generally characterized by a laminar flow nature without turbulent mixing [1] and by certain nonlinearities resulted from the interfacial effects [2-5]. The determinatives behind these phenomena include the viscous forces which often dominate over the inertial forces in controlling the fluid flow (i.e., low Reynold's number) and, with a presence of a fluid interface, the interfacial tension, which is usually more decisive than the shear stress therein (though the effect might be inverse as either fluid viscosity or velocity becomes extremely high to override the interfacial tension). Nevertheless, microflow offers unique advantages to mass and heat transfer such as reduced transport distance, large surface-to-volume ratio, and, more importantly, precise and efficient control over fluid flows [6-8], and thus it draws ever-increasing attention from both academia and industry for fundamental and applied studies.

Following a few pioneering experimental studies specifically on two-phase microflows in early 2000s $[2,9,10]$, numerous studies have been performed on liquid-liquid and gas-liquid flows in microfluidic geometries. Most of them focused on the fluid-fluid (hydrodynamic) interactions and the characterization and analysis of the following functions such as breakup of one flow stream into fluid segments as well as its mechanics [4,11-17], development of various flow patterns [4,5,18-22], and the scaling characteristics (e.g., length or volume) of the emulsified monodispersed droplets or bubbles [4,21,23-27]. One of the most examined geometries among these studies on generating and manipulating fluid

*Corresponding author: c3ren@uwaterloo.ca segments is the T-junction (the main type of cross-flowing junctions, others including $\mathrm{Y}$ - and $\mathrm{H}$-junctions etc.), which has gained popularity because of its simple design and capability of producing uniform droplets [28,29].

A typical T-junction consists of a main channel accommodating the continuous phase of fluid and a perpendicularly aligned side channel filled with the dispersed phase of fluid. For a pair of fluids in a given T-junction, they may operate in various flow regimes like drop flows in confined or unconfined geometries and steady-state coflows or parallel flows where two fluids flow side by side resulting from the applied flow rates $\left(10^{-2}\right.$ to $\left.10 \mu \mathrm{l} / \mathrm{min}\right)$ as well as the capillary number (the strength of tangential shear stress relative to interfacial tension) [29]. Due to their physical merits (e.g., no axial dispersion and enhanced mixing within flowing segments) over continuous microfluidics and the attempted applications in fabricating special materials or in screening and analyzing (bio-)chemical reaction products, drop flows in the microfluidics domain have received excessive attention over the past 15 years or so, in particular, on the fundamental physical aspects of drop generation [30]. Thorsen et al. [2] were deemed the first to utilize a micro-T-junction for producing water-in-oil emulsions where water droplets were produced in an unconfined geometry (the fluid-fluid boundary is not static and never touches the channel wall). They outlined that the droplet production was driven by the instability as a result of shear stresses competing with surface tension, which had been analogously revealed by Taylor [31], who correlated the drop straining in terms of length and breadth variations and the drop "bursting" with a dimensionless number (i.e., capillary number) and the viscosity ratios of the two fluids. Later, models predicting the sizes of unconfined T-junction-borne drops were developed from the standpoint of force balance of the emerging droplet, where the considered forces included but not were limited to the cross-flowing drag forces imposed by the continuous fluid, the interfacial tension forces as well 
as pressure forces on or across the interface, and the inertial forces due to the relative motion [32-34]. These models show a strong correlation between the droplet size and capillary number (calculated based on the continuous fluid); in other words, the shear stresses show an imprint on the unconfined breakup of drop as well as the final drop size when a fixed set of fluids (interfacial tension as a constant) are considered [29].

The other type of droplet breakup distinct from the unconfined one is exactly the confined droplet generation, in which the dispersed emerging drop is capable of filling the whole main channel obstructing the continuous phase before the breakup occurs. Note that the obstruction to the continuous fluid is not $100 \%$ complete though the interface of the emerging drop seems to reach the channel wall. Because the continuous and dispersed phase preferably wet the channel wall, a thin film exists of the continuous fluid separating the drop and channel wall. Consequently, the upstream pressure within the continuous fluid increases $[1,35]$ and drives the interface toward a pinch-off position which may locate near the inner corner of the T-junction (a more common scenario, especially for studies of scaling droplet sizes) or a certain distance downstream away from it $[5,33,36]$. When the neck reaches a critical value, the dispersed (emerging) fluid is then squeezed into a droplet (or a segment whose length is several times larger than the channel width). Garstecki et al. [4] experimentally investigated the mechanism of squeezing and breakup of droplets (and bubbles as well) confined in different $\mathrm{T}$-junctions under a wide range of flow rates $\left(10^{-3}\right.$ to $\left.10^{-1} \mu \mathrm{l} / \mathrm{s}\right)$ and various liquid viscosities $(10$ and $100 \mathrm{mPa} \cdot \mathrm{s})$. It was demonstrated that under low capillary numbers $\left(\mathrm{Ca}<10^{-2}\right)$ the upstream pressure buildup due to the obstruction of the dispersed fluid dominates the dynamics of the droplet breakup, and the resulting droplet lengths $(L)$ are determined by both the squeezing time (inversely proportional to the flow rates of the continuous fluid, $Q_{c}$ ) and the emerging drop growth rates (approximated by the flow rates of the dispersed fluid, $Q_{d}$ ). Their relationship can be formulated as $L / W=1+\alpha Q_{d} / Q_{c}$ where $W$ and $\alpha$ are the width of the main channel and a constant of order one related to the specific T-junction geometry, respectively. This flow-rate-controlled squeezing breakup mechanism of droplets at low Ca was later verified by their numerical simulations through which a critical $\mathrm{Ca}\left(\mathrm{Ca} \sim 10^{-2}\right)$ was identified. Beyond this critical $\mathrm{Ca}$ the shear stresses start to manifest in deforming the emerging droplet, and subsequently, the shear-controlled dripping and jetting regime of droplet generations are initiated [5]. Based on the insights into the three-dimensional flow field in the vicinity of the interface [12] and a perspective that the pinch-off is caused by a combination of interface curvature variations, a pressure gradient, and a reverse flow of the continuous fluid which goes through the gutter region (separating the interface from the channel wall) [14], van Steijn et al. [27] proposed a closed-form model for predicting the droplet volume $\left(V_{\text {Drop }}\right)$ produced in a confined squeezing regime, i.e., $V_{\text {Drop }} /\left(D W^{2}\right)=V_{\text {fill }} /\left(D W^{2}\right)+\alpha Q_{d} / Q_{c}$, where $V_{\text {fill }}$ and $D$ are the volume of the emerging drop after the filling stage and the depth of the channel, respectively. The authors indicated that $V_{\text {fill }}$ and $\alpha$ are in general fully dependent on the geometry of the T-junction. Thus, the factors of T-junction geometry and three-dimensional flow are also important besides the flow rates, and more significantly, fitting parameters become unnecessary [37]. In addition to the pressure-dominated squeezing regime and the shear-driven dripping and jetting regime, there is likely a transitional regime in which both the pressure fluctuations and shear stresses take effect in the droplet breakup dynamics [5,29,37]. Such a model for describing the characteristics (e.g., the geometries, the force balance, and the pinching-off prediction) of drop formation operating in the transitional regime was provided by Glawdel et al. [38].

Unlike the common immiscible fluid pairs applied to produce either emulsions (e.g., oil-in-water or water-in-oil) or foams [e.g., air-glyrerol, nitrogen-(glycerol mediated water), air-ethanol, etc.] in the aforementioned microfluidic studies, this study focuses on a partially miscible "liquid-liquid" pair of liquid carbon dioxide $\left(\mathrm{CO}_{2}\right)$ and water. Despite limited studies dedicated to the hydrodynamics of miscible (even partially miscible) fluids in microscale geometries [39-44], $\mathrm{CO}_{2}$ ranging from gas and liquid to its supercritical state has been employed as one of the phases in two-phase microfluidic flows for multiple applications in green chemistry, nanomaterial syntheses, and environmental science over the past decade (see Table I), where the other phase is often an aqueous fluid. Two aspects of the $\mathrm{CO}_{2}$-water system are of great interest to both scientific and technological domains: one is the tunable physical properties (e.g., viscosity, density, diffusivity, etc.) of $\mathrm{CO}_{2}$ in quite wide ranges via merely adjusting its pressure or temperature plus other practical benefits such as being nontoxic or inert among others; the other is rooted in the solubility of $\mathrm{CO}_{2}$ in water, which is of certain significance to chemical, environmental science, and even food industries. As such, the $\mathrm{CO}_{2}$-water system becomes one of the most studied fluid pairs in physical chemistry [45]. In view of Gibbs energy change $(\Delta G)$ at room temperature, the $\mathrm{CO}_{2}$-water system at room temperature is very likely a nonmixed two-component one which is featured with an albeit-hypothetical positive $\Delta G$ [46] by accounting for the solubility of $\mathrm{CO}_{2}$ in water (molar fraction $\leqslant 0.03$ mole $/$ mole for pressures and temperatures ranging from 0 to $200 \mathrm{bar}$ and 0 to $110^{\circ} \mathrm{C}$, respectively) [47,48]. On the other hand, the addition of $\mathrm{CO}_{2}$ in an aqueous liquid indeed increases the effective viscosity of the bulk fluid under equilibrium conditions, and the bubbly $\mathrm{CO}_{2}$ results in certain visco-elasticities of the multiphased suspension with varying rheology [49]. Despite the $\mathrm{CO}_{2}$-water system confined in micro-geometries having been treated as one sharp-interface model [50], it is still unclear whether the dissolved $\mathrm{CO}_{2}$-in-water interface (in particular on a molecular level) exhibits analogous interfacial effects as their immiscible counterparts do. If not, what could be the differences in terms of interfacial hydrodynamics and the characteristics of the produced liquid compartments?

To answer these questions and to facilitate the development of microscale $\mathrm{CO}_{2}$-water fluid theories and their applications to various fields, this study experimentally investigates the transport phenomena of $\mathrm{CO}_{2}$-water confined in a micro-Tjunction where the dense and viscous water is the continuous phase and the not very light but much less viscous liquid $\mathrm{CO}_{2}$ is the dispersed phase.

The paper proceeds as follows. Section II presents the experimental system and methods for studying, in particular, high-pressure two-phase microfluidics. In Sec. III, we show 
TABLE I. Application examples of $\mathrm{CO}_{2}$ as a phase in microfluidic systems.

\begin{tabular}{|c|c|}
\hline Application & Reference \\
\hline \multicolumn{2}{|l|}{ Chemical reaction } \\
\hline As solvent or co-solvent & Kobayashi, Mori and Kobayashi [51]; Benito-Lopez et al. [52]; Trachsel et al. [53]. \\
\hline As solvent for extraction & Luther and Braeuer [54]; Assman, Kaiser and von Rohr [55]; Assman et al. [56]. \\
\hline \multicolumn{2}{|l|}{ Chemical properties } \\
\hline Solubility & $\begin{array}{l}\text { Tumarkin et al. [57]; Abolhasani et al. [58]; Liu et al. [59]; } \\
\text { Cubaud, Sauzade, and Sun [60]. }\end{array}$ \\
\hline Diffusivity & Fadaei, Scarff, and Sinton [61]; Sell et al. [62]. \\
\hline \multicolumn{2}{|l|}{ Material synthesis } \\
\hline As a solvent & Marre et al. [63]; Gendrineau et al. [64]. \\
\hline \multicolumn{2}{|l|}{ Transport and distribution } \\
\hline In microchannels & $\begin{array}{l}\text { Marre et al. [65]; Ohashi et al. [66]; Blanch-Ojea et al. [67]; Guillaument et al. [68]; Luther et al. [69]; } \\
\text { Ogden } \text { et al. } \text { [70]. } \\
\text { Knaust } \text { et al. }[71] .\end{array}$ \\
\hline In microscale porous media & Zhang et al. [72]; Kim et al. [73]; Wang et al. [74]; Kim, Sell \& Sinton [75]; Kazemifar et al. [76]. \\
\hline Review articles & Marre et al. [77]; Abolhasani et al. [78]. \\
\hline
\end{tabular}

the observations from experiments including the drop flow and coflow regime, and we detail each stage of one period of the drop generation for drop flow. Focusing on the drop flow, Sec. IV shows the drop length, after-generation drop speeds, and spacing development between an emerging drop and the newly produced one. Section V concludes our experimental observations. In paper II we provide theoretical justifications to our quantitative studies on the drop flow and mathematical models for the drop length and the drop spacing.

\section{EXPERIMENTAL SYSTEM AND METHODS}

The experimental system (see Fig. 1) consists of a reactant feeding system (tanks and syringe pumps), a microfluidic system (a nonpermanent connector and microfluidic chips), an imaging system (a microscope and a high-speed camera), pressure-temperature control systems (mainly a back pressure regulator and a water circulator), and stainless steel tubing for fluidic connections. This experimental system has been dedicated to studies related to the experimental aspects of twophase microfluidics, especially those under extreme conditions [i.e., high pressures (up to $10 \mathrm{MPa}$ ) and/or high temperatures (up to $200-300^{\circ} \mathrm{C}$ )]. Based on this system and a silicon-glass microfluidic chip, liquid $\mathrm{CO}_{2}$ and water two-phase flows at a microscale $\mathrm{T}$-junction have been visualized and investigated thence.

Two syringe pumps (260D and 100DM, Teledyne Isco) are utilized to regulate the flow rates and/or pressures of the two preloaded fluids, namely, liquid $\mathrm{CO}_{2}$ (Praxair Canada) and deionized (DI) water. The back pressure of the flow in the microfluidic channels and the related tubing can be managed by a back pressure regulator (BPR, model EB1ULF1, Equilibar) together with a setting pressure provided from a gaseous $\mathrm{N}_{2}$ tank (Praxair Canada). As a reference pressure, the setting pressure is applied to the BPR through regulating the $\mathrm{N}_{2}$ gas by a gas regulator right at the outlet of the tank. Technically, only when the back pressure of the outflow from the microchip (also as an inflow pressure of the BPR itself) surpasses the setting pressure can fluids flow through and maintain a constant flow thereafter. During the experiments, the practical back pressure is measured by a pressure transducer (Swagelok) placed upstream of the BPR. Prior to entering to the

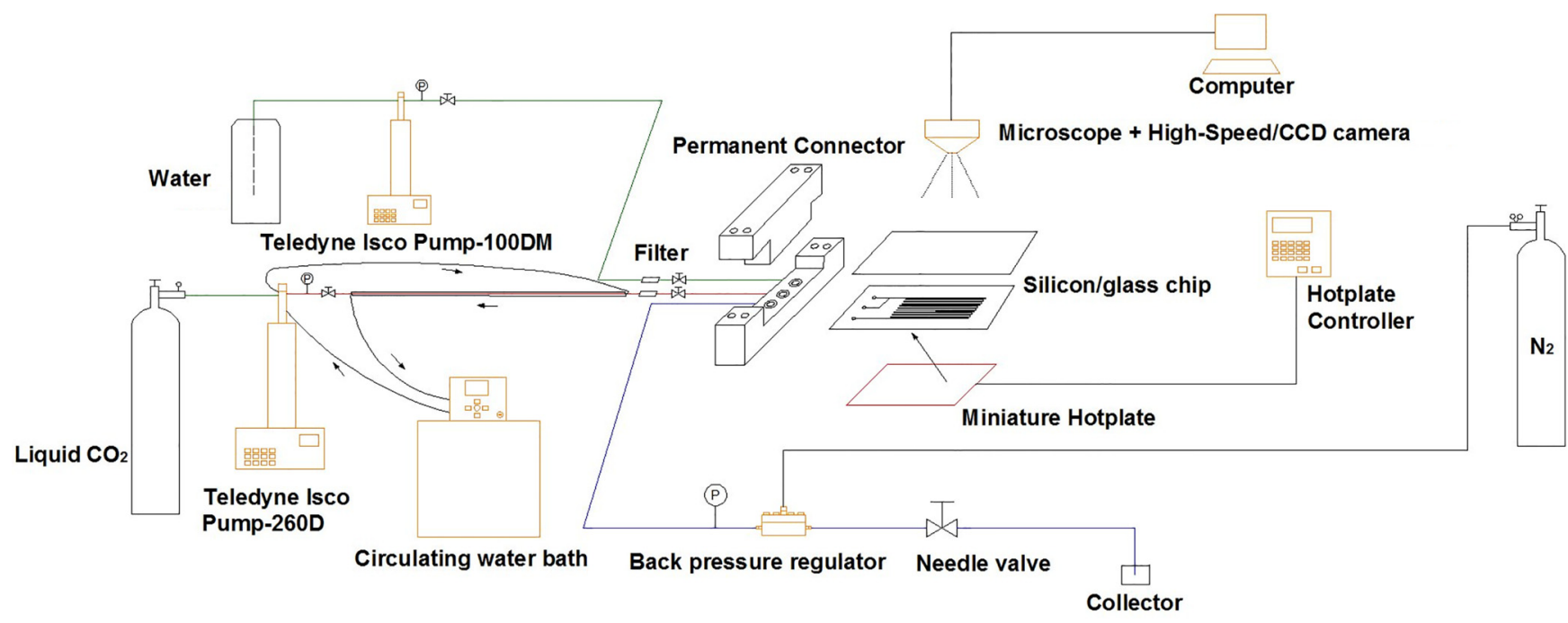

FIG. 1. Schematic of the experimental system. 
(a)

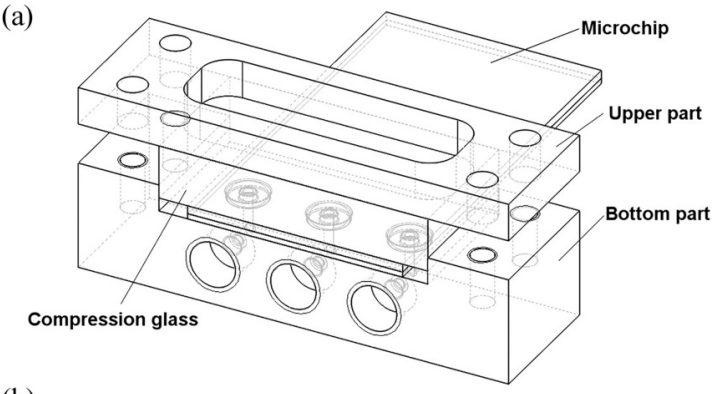

(b)

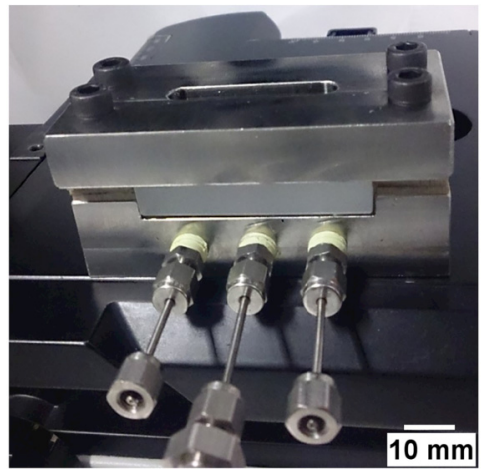

FIG. 2. Assembly of a nonpermanent connector and a microchip: (a) schematic of a nonpermanent connector including an upper part, a bottom part, a compression glass cuboid, and three $\mathrm{O}$ rings (not shown here) placed in the three grooves as well as between the microchip and the bottom part; (b) a photo of the assembly where the connection fittings and four screws is also shown.

microfluidic system, liquid $\mathrm{CO}_{2}$ and water are filtered by two in-line $2 \mu \mathrm{m}$ particulate filters (Swagelok) installed at the inlets of the chip connector, in order to prevent potential clogging caused failures of the microchannels. Besides, a circulating water bath (Thermo Scientific) and a miniature hotplate (model ph-121s, MSA Factory Co.) are available, respectively, for controlling the temperature of the $\mathrm{CO}_{2}$ not only in the pump but also in the tubing and the temperature of the micromodel.

A nonpermanent connector as shown in Fig. 2, partly based on the guidance from Ref. [79], has been designed and machined in a lab for bridging fluid connections from macrotubing to microchannels. It is composed of (1) a robust compression upper part (316 stainless steel), (2) a bottom part with fluidic features (316 stainless steel), (3) a borosilicate glass cuboid $(49.8 \mathrm{~mm} \times 25 \mathrm{~mm} \times 10.2 \mathrm{~mm})$ ensuring a uniform compression between the upper and bottom parts, and (4) three Viton fluoroelastomer O rings (AS568-004, Duro 90A) placed in the specifically designed grooves of the bottom part.

The central openness of each groove element connects to a $1 / 16$ inch female NPT (National Pipe Tapered Thread) featured hole on the side facing to the incoming fluids of the connector. Three straight fittings housing the stainless steel tubing are employed to interlink the tubing with the nonpermanent connector by their threads matching eventually.

\section{A. Fabrication of a micromodel}

Due to their excellent gas impermeability, durability under extreme conditions and inert chemical properties, etc., siliconglass microchips are chosen as the micromodel for this
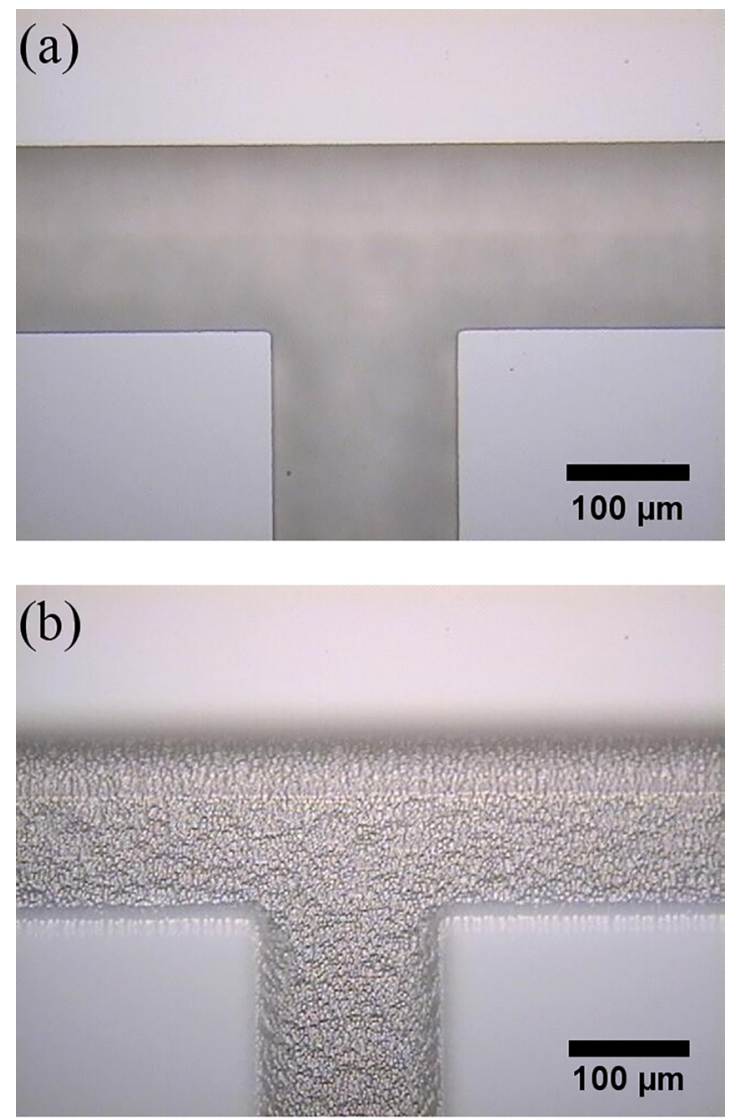

FIG. 3. A silicon-glass microchip featured by a micro-T-junction: (a) a top view of the micro-T-junction and (b) the channel bottom with a certain degree of roughness resulted from the deep reactive ion etching (DRIE). Scale bars: $100 \mu \mathrm{m}$.

study. A silicon wafer (4 inches in diameter, $\langle 100\rangle$ single side polished, $525 \mu \mathrm{m}$ thick) and a glass wafer (4 inches diameter, double side polished, $700 \mu \mathrm{m}$ thick, Borofloat 33, Schott AG) are used as the substrates to fabricate a siliconglass microchip. The fabrication proceeds in the sequence of (1) standard photolithography, (2) deep reactive ion etching (DRIE) [80], (3) inlet and outlet drilling and wafer cleaning, (4) anodic bonding of silicon and glass wafer, and (5) dicing of the bonded wafers into a final size $\left(74 \times 44 \times 1.2 \mathrm{~mm}^{3}\right)$. Detailed procedures of the fabrication can be found in the Supplemental Materials (S1) [81]. After the DRIE but prior to wafers bonding, the channel size of the T-junction is examined under a microscope (a 20× objective applied, Nikon Eclipse) mounted with a camera (model KP-D50, Hitachi). Figure 3(a) shows a top view of the T-junction from which the channel width is measured using ImageJ (version 1.48, National Institutes of Health, USA), and Fig. 3(b) shows the bottom of the channels featured by DRIE-caused roughness. Based on a focusing shift from the top to the bottom of the channel through turning the fine focus knob of the microscope, channel depth $(D)$ can be estimated. The width $(W)$ and the depth $(D)$ of both the main channel and the side channel are $(150 \pm 2.5) \mu \mathrm{m}$ and $(100 \pm 2) \mu \mathrm{m}$, respectively. 


\section{B. Micro-to-macro-connection}

A leakage-free (not only for the microchip connections but also for the whole system), safety-ensured (with respect to the microchip) assembly of the microchip and the connector is extremely crucial to a successful initiation and operation of the experiment. For a verification of leakage-free of the assembly, the system, filled with pressurized $\mathrm{CO}_{2}$ and with the valves on two sides of the assembly completely closed, has been monitored in terms of the pressure values as a function of time (up to $20 \mathrm{hr}$ ). Only when the pressures are steadily equivalent to the initial value can the assembly be assumed to have no leakage. Although a reasonable tighter screwing leads to a better sealing, it is, however, very likely to crush the microchip itself due to an overcompression and/or nonuniform compressions. After a few bitter attempts and failures, we find that an as-uniform-as-possible hand tightened-to-the-most screwing provides a sealing without any leakage and results in no compromise on the safety of the microchip as well under a pressure up to 80 bar. Another finding is that after the test especially a long one the $\mathrm{O}$ rings having been in contact with the high-pressure $\mathrm{CO}_{2}$ expands in sizes, namely, inner diameters and outer diameters and thicknesses, depending on the tested pressures and the test durations. The size expansion of the $\mathrm{O}$ ring is attributed to the $\mathrm{CO}_{2}$ diffusion that is further intensified by the high pressure (rather than normal-pressure applications), long diffusion time $(\sim 20 \mathrm{hr})$, and the small ring size. Albeit no leakage or fracture resulted, this issue draws attention to hazards related to high-pressure applications and long contact time of the $\mathrm{O}$ rings. Therefore, it is necessary to release the high-pressurized fluids (i.e., $\mathrm{CO}_{2}$ and $\mathrm{H}_{2} \mathrm{O}$ ) off from the microchannels and the connector channels as soon as the test or the experiment ends. Moreover, whatever fluids filling-in or releasing-off it needs to be conducted slowly and gently since the rates of pressure change other than absolute pressure values can also impact the variations of stresses of the microchannels and the interfacial ports so as to their integrities.

\section{Experimental visualization and measurements}

Liquid $\mathrm{CO}_{2}$ and DI water are used as the dispersed phase flowing in the side channel and the continuous phase flowing in the main channel, respectively, and encounter at the Tjunction [Fig. 4(a)]. The flow phenomena at the T-junction are visualized using a microscope (BX51, Olympus) mounted with a high-speed camera (v210, Phantom). This camera is capable of capturing images at 2000 frames per second (fps) at the full $1280 \times 800$ resolution, and faster frame rates can be achieved at reduced resolutions. Over all the flow conditions in this study, a $10 \times$ objective together with a frame rate of no lower than $5000 \mathrm{fps}$ that resulted in a $304 \times 800$ resolution is applied, and only when the drop length or drops spacing is oversized (larger than $5 \mathrm{~W}$ ) do we additionally employ a $5 \times$ objective as well as a $3000 \mathrm{fps}$ frame rate and a $560 \times 800$ resolution. Compared with the halogen lamp, the mercury lamp of the microscope together with an external power supply (BH2-RFL-T3, Olympus) can provide a better illumination with a higher intensity and is thus applied. Based on the frames-stacked videos showing the flows at the T-junction, descriptive parameters (e.g., drop length, drops spacing, and drop speed), as shown in Fig. 4(a), of the liquid $\mathrm{CO}_{2}$ drops become measurable. Raw videos

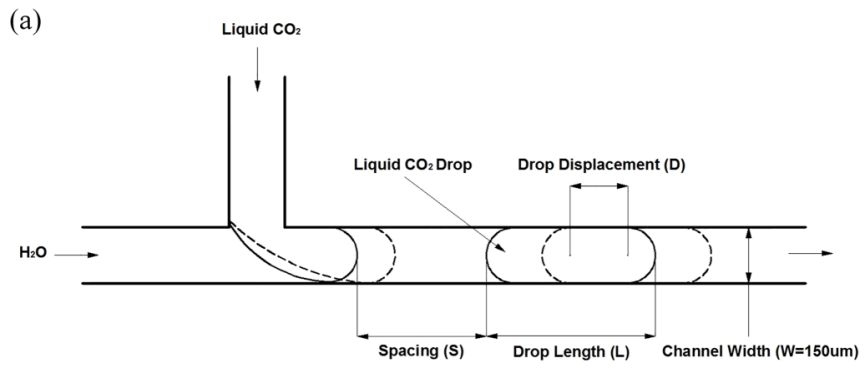

(b)

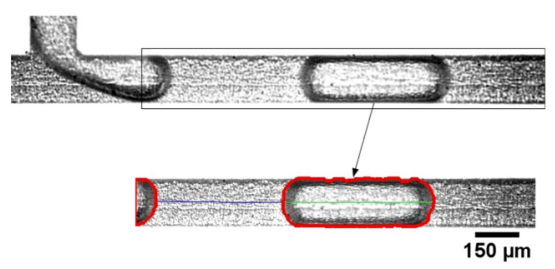

FIG. 4. An example of liquid $\mathrm{CO}_{2}$ and water two-phase flow in a micro-T-junction where liquid $\mathrm{CO}_{2}$ drops are being produced. (a) Schematic of a newly generated liquid $\mathrm{CO}_{2}$ drop and a second one starts formation: solid lines and dash lines depict the drops at the $i$ th and the $(i+1)$-th frame, respectively, during one period of drop generation. Parameters to be measured include (I) drop length $L$, (II) drop spacing $S$ between the emerging drop and the adjacent formed one within one period, and (III) drop speed $V$ determined by the drop displacement $\Delta d$ (centroid to centroid) during one time interval $\Delta t$ of the frames. (b) A sample of frame selected from the experiment video. The image below shows the identification of a formed drop and the measurements of drop length $L$ and drop spacing $S$ using the same frame in Matlab.

from the experiment are first adjusted to their best qualities in terms of brightness, contrast, and/or color balance and are then cropped to the sizes $(185 \times 800$ from using $10 \times$ objective and $95 \times 800$ from using $5 \times$ objective, respectively) of interest for the following processing, both of which are done using the software ImageJ. Afterwards, the videos are imported to Matlab (R2014a, Mathworks), and the above parameters can be measured taking advantage of a series of self-developed Matlab codes based on the identification of drops [Fig. 4(b)].

\section{Experimental procedure}

Prior to the experiment, a water bath at a temperature of $(25 \pm 0.4)^{\circ} \mathrm{C}$ (the room temperature $25^{\circ} \mathrm{C}$ ) is circulated within the vinyl tubing (enclosing the circulating water as well as the stainless steel tubing) and a temperature control jacket (for the $\mathrm{CO}_{2}$ cylinder) of the $\mathrm{CO}_{2}$ pump for 30 minutes in order to maintain the $\mathrm{CO}_{2}$ temperature at $25^{\circ} \mathrm{C}$. With a setting pressure of $\left(64 \pm 1\right.$ ) bar (shown by the $\mathrm{N}_{2}$ tank regulator) applied at the $\mathrm{BPR}$, liquid $\mathrm{CO}_{2}$ from its pump infuses into the stainless tubing and the on-chip microchannels in a controlled way by slowly opening two $\mathrm{CO}_{2}$-side valves (installed upstream of the connector). During this process, two water-side valves are kept closed to prevent the infused $\mathrm{CO}_{2}$ from entering the water pump. Due to a lower pressure ( $\sim 60$ bar) than 64 bar, infused $\mathrm{CO}_{2}$ will not rush through the BPR but stays within the microchannels and the tubing. Afterwards, a constant flow rate of $50 \mu \mathrm{l} / \mathrm{min}$ is applied to 
$\mathrm{CO}_{2}$, and the pump piston's continuous compression results in the $\mathrm{CO}_{2}$ pressure increases. Only until the pressure reaches the setting pressure will the BPR diaphragm be jacked up to allow $\mathrm{CO}_{2}$ flows through at that flow rate. The real back pressure measured by the pressure transducer at present is 65 bar. Using the water pump the pressure of DI water is raised to 65 bar in advance and a constant flow rate of $50 \mu \mathrm{l} / \mathrm{min}$ is given, and then the two water-side valves are slowly opened to let the water enter its tubing and the microchannels. The two liquids are very likely to meet between the close-to-connector valve (in Fig. 1) and the T-junction on-chip. Within 1 minute or so, liquid $\mathrm{CO}_{2}$ and water can be observed and start to interact constantly at the T-junction.

Following the first flow condition $\left[Q_{\mathrm{H}_{2} \mathrm{O}} / Q_{L \mathrm{CO}_{2}}=\right.$ $50(\mu \mathrm{l} / \mathrm{min}) / 50(\mu \mathrm{l} / \mathrm{min})]$, more flow cases in terms of different combined flow rates of liquid $\mathrm{CO}_{2}$ and water have been investigated. These cases (Table II) numbered from 1 to 28 can be categorized into two groups: the first group (case 1 to 21 with case 12 as an exception) has a constant total flow rate $\left(Q_{L \mathrm{CO}_{2}}+Q_{\mathrm{H}_{2} \mathrm{O}}=100 \mu \mathrm{l} / \mathrm{min}\right)$ while the flow rate of $\mathrm{CO}_{2}$ is first increased and then decreased and the flow rate of water is first decreased and then increased; the second group (case 22 to 28) is featured by a constant flow rate of liquid $\mathrm{CO}_{2}\left(Q_{L \mathrm{CO}_{2}}=50 \mu \mathrm{l} / \mathrm{min}\right)$ as well as stepwise ascending flow rates of water from $100 \mu \mathrm{l} / \mathrm{min}$ up to $500 \mu \mathrm{l} / \mathrm{min}$. Case 12 was designed to test the minimum flow rate ratio that still results in coflow. Sequentially, when a new pair of flow rates are applied, the videos of this case are recorded after a waiting time of 30 minutes when the flow regime is deemed as stabilized.

(a)

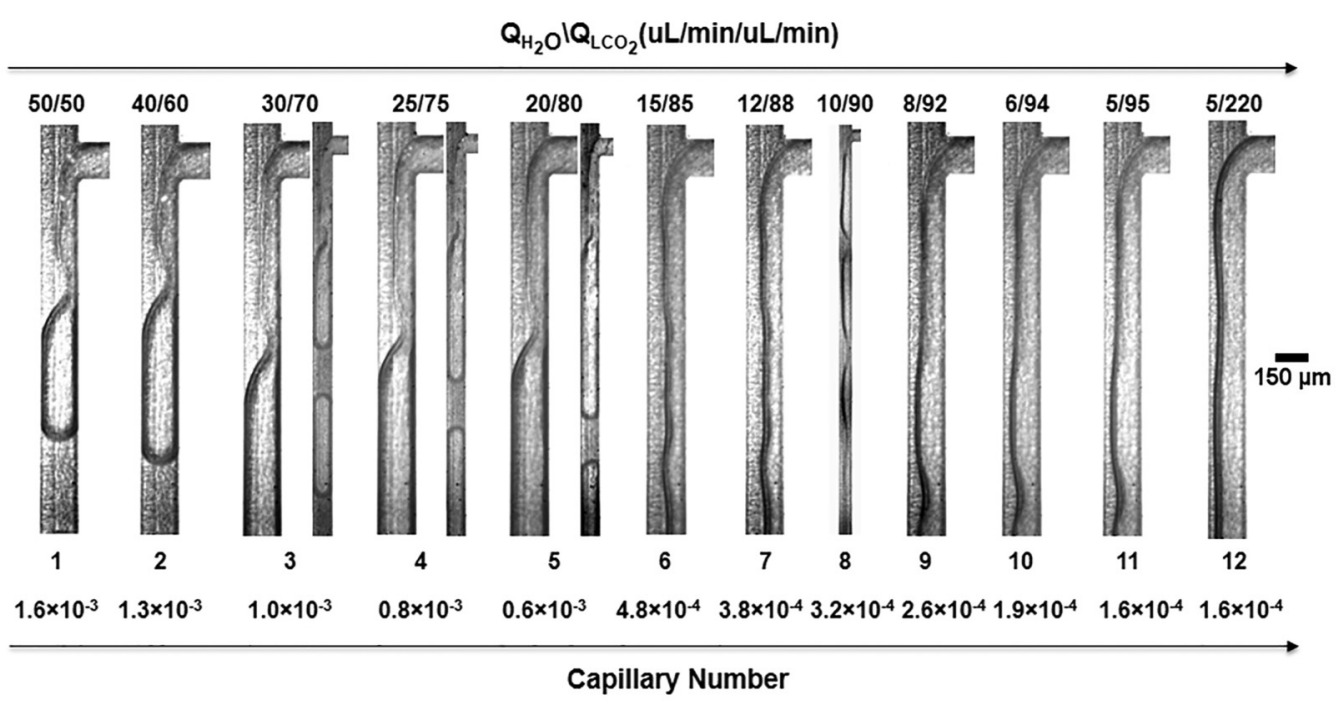

(b) $Q_{\mathrm{H}_{2} \mathrm{O}} \backslash Q_{\mathrm{LCO}_{2}}(\mathrm{uL} / \mathrm{min} / \mathrm{uL} / \mathrm{min})$

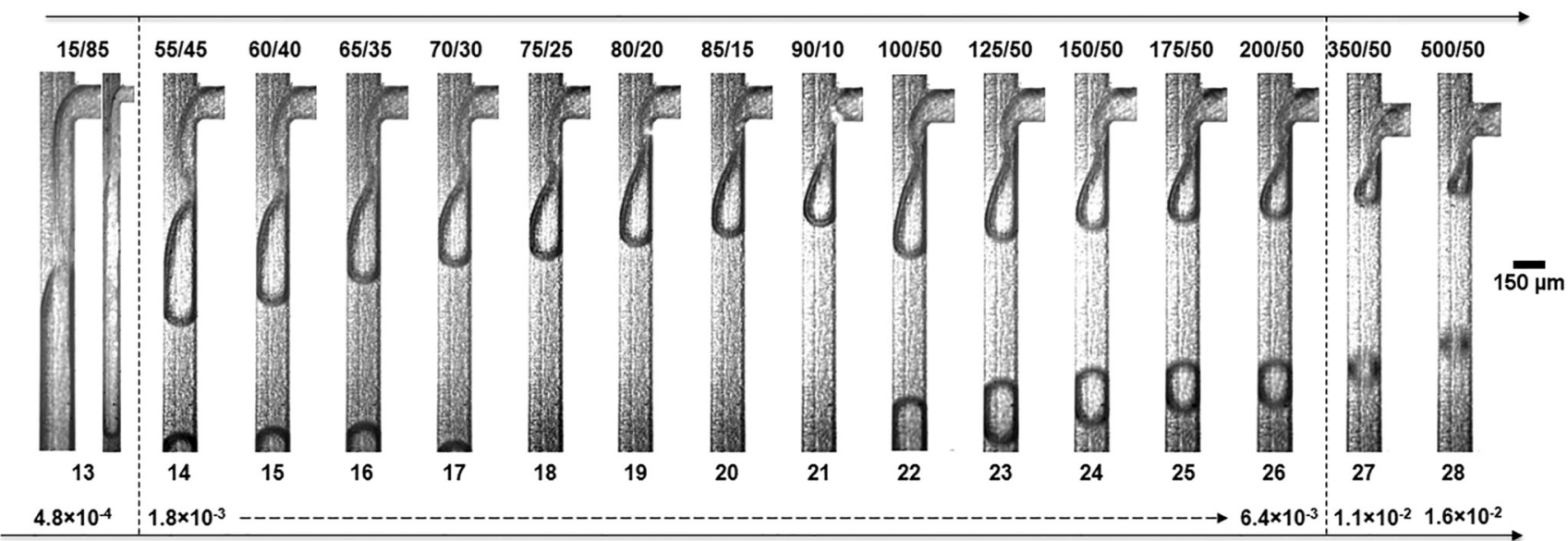

Capillary Number

FIG. 5. Flow regimes of liquid $\mathrm{CO}_{2}$ and water two-phase flow at a T-junction as a function of flow rate ratio $Q_{\mathrm{H}_{2} \mathrm{O}} / Q_{L_{\mathrm{CO}}}$ and Ca $\mathrm{C}_{c}$ number: liquid $\mathrm{CO}_{2}$ enters from the side channel as the dispersed phase and water flows in the main channel as the continuous phase of the T-junction. (a) The flow rate ratio $Q_{\mathrm{H}_{2} \mathrm{O}} / Q_{\mathrm{LCO}_{2}}$ and $\mathrm{Ca}_{c}$ number are decreased from $50 / 50$ to $5 / 220$ and $1.6 \times 10^{-3}$ to $1.6 \times 10^{-4}$, respectively. Cases 3 to 5 are all shown by two frames captured using a $10 \times$ (left) and a $5 \times$ objective (right). Case 8 is shown by an end-to-end combination of three frames from using the $5 \times$ objective. (b) From case 13 to $21, Q_{\mathrm{H}_{2} \mathrm{O}} / Q_{L \mathrm{LO}_{2}}$ and $\mathrm{Ca}_{c}$ number are both increased due to the flow rate increase of water; from case 22 to 28 , water flow accelerates from 100 to $500 \mu \mathrm{l} / \mathrm{min}$ while the liquid $\mathrm{CO}_{2}$ is maintained as a constant flow. As $\mathrm{Ca}_{c}$ reaches $O\left(10^{-2}\right)$, it leads to a dripping regime (cases 27 and 28) of the drop flow. 


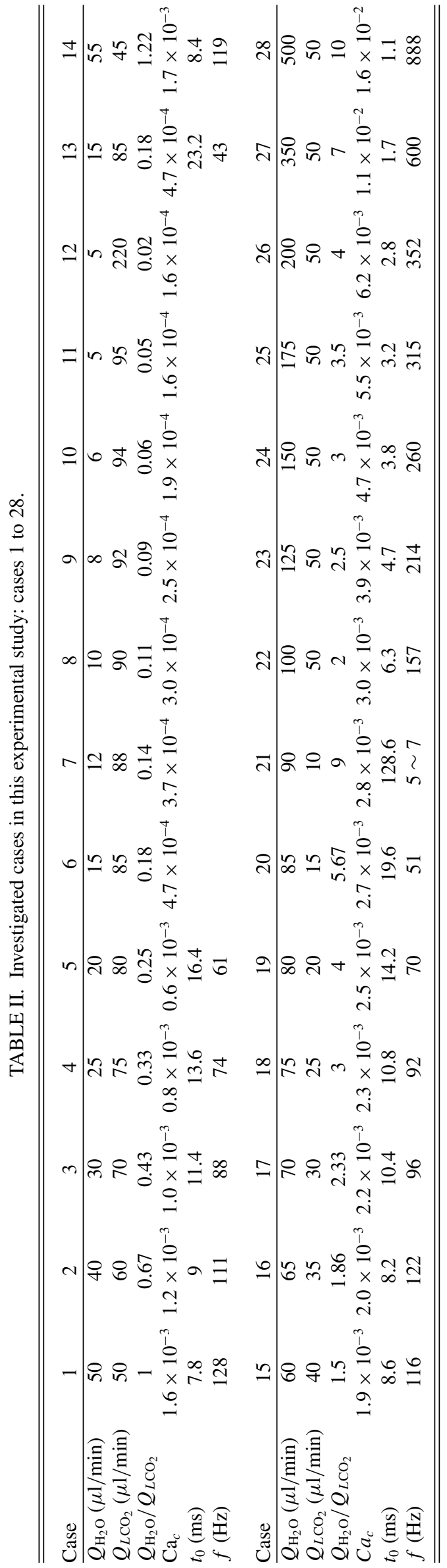

\section{EXPERIMENTAL OBSERVATIONS}

Flow regimes of the 28 cases are shown as a function of $Q_{\mathrm{H}_{2} \mathrm{O}} / Q_{\mathrm{LCO}_{2}}$ and $\mathrm{Ca}_{c}$ number (see Fig. 5) by selecting either the frames at the end of their truncating stages (for drop flows) or representative frames of the coflows. Table II also provides two parameters that are derivable from the two flow rates: flow rate ratio $\left(Q_{\mathrm{H}_{2} \mathrm{O}} / Q_{L \mathrm{CO}_{2}}\right)$ and capillary number $\mathrm{Ca}_{c}\left(\mathrm{Ca}_{c}=\right.$ $\left.\eta_{c} u_{c} / \gamma\right)$ of the continuous phase-water. Here $\eta_{c}, u_{c}$, and $\gamma$ are the dynamic viscosity $\left(\eta_{c}=890 \mu \mathrm{Pa} \mathrm{S}\right.$ at $298 \mathrm{~K}$ and 65 bar [82]) of water, the mean velocity $\left[u_{c}=Q_{\mathrm{H}_{2} \mathrm{O}} /(D\right.$. $W)$ ] of the water phase through the entire cross section of the channel and the quasi-equilibrium interfacial tension $[\gamma=$ $(31.7 \pm 0.3) \mathrm{mN} \cdot \mathrm{m}^{-1}$ ] of water with liquid $\mathrm{CO}_{2}$ based on Refs. [83] and [84], respectively.

\section{A. Drop flow}

Figure 6 shows some snapshots of a drop flow which resulted from the set of flow conditions $\left(Q_{\mathrm{LCO}_{2}}=50 \mu \mathrm{l} / \mathrm{min}\right.$ and $Q_{\mathrm{H}_{2} \mathrm{O}}=50 \mu \mathrm{l} / \mathrm{min}$ ) and is characterized by a periodic generation of liquid $\mathrm{CO}_{2}$ drops. The period is mainly composed of, in a chronological order, a stagnating and filling stage, an elongating and squeezing stage, and a truncating stage.

\section{Stagnating and filling}

Immediately after a drop is produced, there is an instant retraction of the ends of the drops (one is the back end of the newly produced drop and the other is the front end of the emerging drop) from the truncation point due to interfacial tension and a transient recovery (or stabilization) of the new interface. This interfacial preparation-like transience does not contribute too much to the advancing of the $\mathrm{CO}_{2}$ front, which gains the name of "stagnating." From this ready-to-go moment until the $\mathrm{CO}_{2}$ portion touches the far-end channel wall, $\mathrm{CO}_{2}$ gradually blocks the cross section of the microchannel as well as the water flow, which is termed "filling." Stagnating versus filling in Fig. 5 is $0.2 \mathrm{~ms}: 1.4 \mathrm{~ms}$. During this stage, the pressure difference between $\mathrm{CO}_{2}\left(P_{c}\right)$ and water $\left(P_{d}\right)$ facilitating the $\mathrm{CO}_{2}$ filling dominates the interfacial variations relative to the Laplace pressure $\Delta P_{L}$, which is determined by the interfacial tension $(\gamma)$ and the radii of curvatures according to YoungLaplace equation.

\section{Elongating and squeezing}

Once the water, as the continuous phase, is blocked, notable pressure is built up in the proximity of the interface on water side, which leads to a resisting effect towards the incursion of the $\mathrm{CO}_{2}$ portion particularly on the upper section (see Fig. 6) of their interface. As the $\mathrm{CO}_{2}$ portion elongates further downstream, its clear upper section is also elongated and simultaneously squeezed almost parallel to the water flow. On the other hand, the shading section starting from the juncture with the clear section to the upper contact point with the far-end wall is pushed downstream as well, which is driven by the continuous phase pressure $\left(P_{c}\right)$ plus the Laplace pressure (more specifically, its component on the flowing direction of water) competing with the within drop pressure. Note that the conjuncture identifying the 

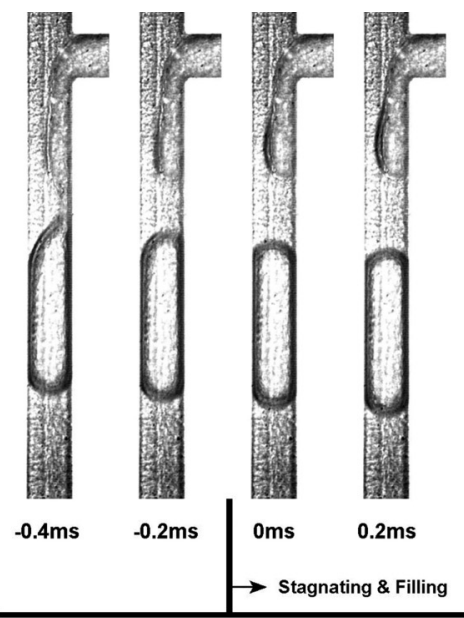

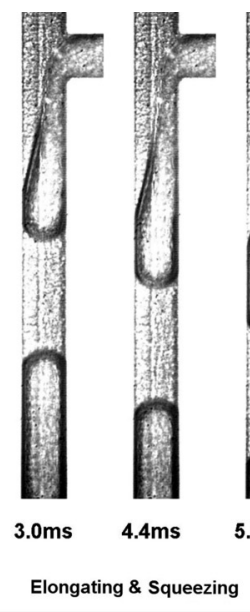

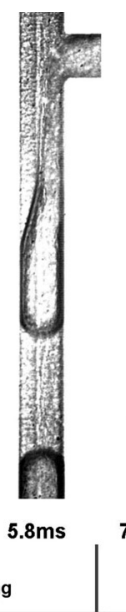

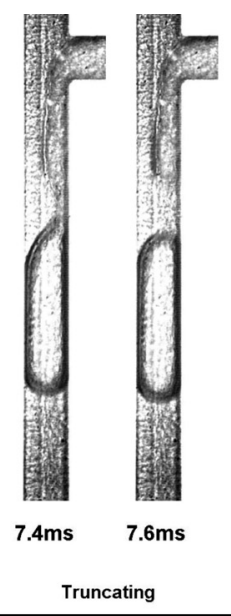

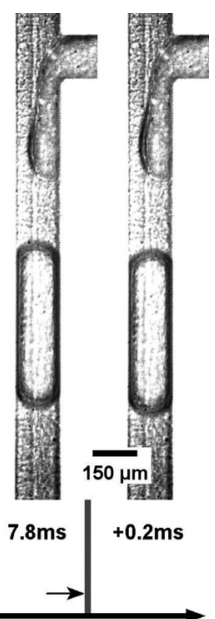

FIG. 6. A quick overview of one period $\left(t_{0}=7.8 \mathrm{~ms}\right)$ of liquid $\mathrm{CO}_{2}$ drop generation during the flow condition where both $\mathrm{CO}_{2}$ and water flow at $50 \mu \mathrm{l} / \mathrm{min}$. Note that the images are rotated $90^{\circ}$ clockwise as compared to Fig. 4 for ease of alignments. The period $t_{0}$ is generally divided into three stages: (a) a stagnating and filling stage $t_{s f}$, (b) an elongating and squeezing stage $t_{e s}$, and (c) a truncating stage $t_{t r}$. And each stage is characterized by a specific time length. Here within one period $t_{0}=7.8 \mathrm{~ms}, t_{s f}, t_{e s}$, and $t_{t r}$ are approximately $1.6 \mathrm{~ms},(6.6-1.6)=5 \mathrm{~ms}$ and $(7.8-6.6)=1.2 \mathrm{~ms}$, respectively.

clear upper section from the shading section also migrates hydrodynamically accompanying the clear section. Once the sum of the continuous phase pressure $\left(P_{c}\right)$ and the Laplace pressure (more specifically, its component perpendicular to the $\mathrm{CO}_{2}$ flow direction) approaches the within drop pressure at the conjuncture, it indicates the end of the second stage and an onset of the next stage.

\section{Truncating}

As long as the pressure conditions are reached, water starts to truncate the emerging drop of liquid $\mathrm{CO}_{2}$. Generally, the truncating commences from the above conjuncture where the Laplace pressure can effectively cope with water to resist the liquid $\mathrm{CO}_{2}$ drop side. During this stage, a concave is formed first at the conjuncture and expands to touch the wall within a very short time (1 ms or so). By this moment, the emerging drop splits into two segments: the front one forming as a complete drop and the back one becoming another emerging drop.

\section{Effects of flow rates}

The time length of each of the three stages within one period of drop formation, according to our observations, is subjected to the flow rate condition. The overviews of one period of drop formation for additional two cases, case $5\left(Q_{\mathrm{H}_{2} \mathrm{O}} / Q_{L \mathrm{CO}_{2}}=\right.$ $20 / 80)$ and case $21\left(Q_{\mathrm{H}_{2} \mathrm{O}} / Q_{L_{C O}}=90 / 10\right)$, which have two extreme conditions of flow rate ratio, are provided in the Supplemental Materials [81] (S2). Compared with that shown in Fig. 6, the total time length of one period of drop formation is longer when $Q_{\mathrm{H}_{2} \mathrm{O}} / Q_{L \mathrm{CO}_{2}}$ is much higher or lower than 1 with approximately $(17 \pm 0.6) \mathrm{ms}$ for case 5 (Fig. S3) and $128.6 \mathrm{~ms}$ for case 21 (Fig. S4).

The time span for the stagnating and filling stage is extremely long $(\sim 100 \mathrm{~ms})$ when the flow rate ratio, $Q_{\mathrm{H}_{2} \mathrm{O}} / Q_{L_{\mathrm{CO}_{2}}}$, is much larger than 1, e.g., case 21 . This long filling time is mainly due to the low flow rate of the disperse phase (liquid $\mathrm{CO}_{2}$ ) which requires a long time to build up sufficiently high pressure at the interface from the $\mathrm{CO}_{2}$ side in order to advance into the T-junction.

In contrast, the time span of the elongating and squeezing stage (i.e., $14 \mathrm{~ms}$ ) is comparatively longer than the first and the third stage when $Q_{\mathrm{H}_{2} \mathrm{O}} / Q_{L_{C O}}$ is much lower than 1, e.g., case 5. The short stagnating and filling time is due to the high flow rate of the disperse phase (liquid $\mathrm{CO}_{2}$ ), which results in a rapid filling of the channel; however, during the second stage, the relatively low flow rate of the continuous phase (water) leads to a slow squeezing of the dispersed stream, thus long time of the elongating and squeezing stage results; also due to low flow rate of water, the truncating time becomes longer than that of case 6 (see Fig. 6).

\section{B. Drop flow to coflow}

As $Q_{\mathrm{H}_{2} \mathrm{O}} / Q_{L_{\mathrm{CO}}}$ is reduced from $50 / 50$ down to $15 / 85$, $\mathrm{Ca}_{c}$ (calculated by water) has a reduction from $O\left(10^{-3}\right)$ to $O\left(10^{-4}\right)$. As a result, a transition of flow regime from drop flow to coflow occurs [see Fig. 5(a)]. As $Q_{\mathrm{H}_{2} \mathrm{O}} / Q_{L \mathrm{CO}_{2}}$ further reduces, there is no more regime transition where coflow becomes a dominant flow regime. The minimum $Q_{\mathrm{H}_{2} \mathrm{O}} / Q_{L \mathrm{CO}_{2}}$ being applied is $5 / 220$ (case 12) and it still results in a coflow regime. However, $\mathrm{CO}_{2}$ stream occupies a larger area (or volume) than water compared with that in case 11. Although even smaller $Q_{\mathrm{H}_{2} \mathrm{O}} / Q_{L \mathrm{CO}_{2}}$ and/or $\mathrm{Ca}_{c}$ is not studied, assume that $Q_{\mathrm{H}_{2} \mathrm{O}}$ approaches $0\left(Q_{\mathrm{H}_{2} \mathrm{O}} / Q_{L \mathrm{CO}_{2}} \approx 0, \mathrm{Ca}_{c} \approx 0\right)$, and this extreme case will eventually lead to a pure $\mathrm{CO}_{2}$ flow.

\section{Drop flow with smaller drops}

The next task is to investigate the cases which are featured by $Q_{\mathrm{H}_{2} \mathrm{O}} / Q_{L \mathrm{CO}_{2}}>1$. As the first step, however, $Q_{L \mathrm{CO}_{2}}$ is reduced from 220 to $85 \mu \mathrm{l} / \mathrm{min}$, and meanwhile $Q_{\mathrm{H}_{2} \mathrm{O}}$ speeds up from 5 to $15 \mu \mathrm{l} / \mathrm{min}$ [case 13 in Fig. 5(b)]. The conditions of case 6 are re-applied here, but the flow regime (even after 30 minutes) seemingly "oversteps" into drop flows rather than 
recurring as a coflow. Instead of using a hysteresis mechanism in terms of the history of the applied flow rates in a comparable study [85], a memory of interfacial force relative to viscous one represented by the Ca number may account for the flow regime drift in a better way. Corresponding to the flow rate variations from case 12 to 13 , local $P_{c}$ and $P_{d}$ may have increased and decreased by a certain extent (although the two pressures are impossible to be measured locally right now, their upstream pressures shown by the pumps have an increase of $6 \mathrm{kPa}$ and a decrease of $2 \mathrm{kPa}$, respectively, while the measured back pressures have no change) than that in case 12 , respectively. If additionally assisted by the interfacial force in memory (much superior over viscous force in case 12 than in case 13), the water phase is very likely to truncate the liquid $\mathrm{CO}_{2}$ stream and thus leads to a drop flow. However, more detailed studies are required to validate our deduction about the inherited effect of interfacial force (varying interfacial tension and/or contact angle might contribute in this), which is beyond the scope of this study. After this case, $Q_{\mathrm{LCO}_{2}}$ is gradually reduced from 45 to $10 \mu \mathrm{l} / \mathrm{min}$ and $Q_{\mathrm{H}_{2} \mathrm{O}}$ keeps increasing from 55 up to $90 \mu \mathrm{l} / \mathrm{min}$ simultaneously [case 14 to 21 in Fig. 5(b)], both of which are performed every $5 \mu \mathrm{l} / \mathrm{min}$ at the pumps. Note that beyond $Q_{\mathrm{H}_{2} \mathrm{O}} / Q_{L_{\mathrm{CO}_{2}}}=90 / 10$ (when $\mathrm{Ca}_{c}=2.8 \times 10^{-3}$ ), there are no more two-phase flows and water occupies the whole channel. Drop generations of case 14 to 21 are basically capable of being described and analyzed taking advantage of the above three stages. As both $Q_{\mathrm{H}_{2} \mathrm{O}} / Q_{L \mathrm{CO}_{2}}$ and $\mathrm{Ca}_{c}$ increase in this range, drop sizes $(L)$ become smaller at least by observations qualitatively. In addition, the truncation points are getting closer to the corner of the T-junction as well; however, it does not imply the drop generation is faster (Table II).

The constant total flow rate of $100 \mu \mathrm{l} / \mathrm{min}$ limits the range of $\mathrm{Ca}_{c}\left(10^{-4}\right.$ to $\left.10^{-3}\right)$ for the study of the effect of $\mathrm{Ca}$ number. Thus, by controlling the liquid $\mathrm{CO}_{2}$ as a constant flow $\left(Q_{\mathrm{LCO}_{2}}=50 \mu \mathrm{l} / \mathrm{min}\right.$ ), the flow rates of water have been increased from $100 \mathrm{up}$ to $500 \mu \mathrm{l} / \mathrm{min}$ in order to provide higher $\mathrm{Ca}_{c}$. Ranging from case 22 to 26 , the drop flows evolves consistently with the trend of previous cases. Given with the cross section area $\left(150 \times 100 \mu \mathrm{m}^{2}\right)$ of the microchannel, only when $Q_{\mathrm{H}_{2} \mathrm{O}}$ exceeds approximately $320 \mu \mathrm{l} / \mathrm{min}$ will the resulting $\mathrm{Ca}_{c}$ be $O\left(10^{-2}\right)$. Cases 27 and 28 are characterized by $\mathrm{Ca}_{c}=1.1 \times 10^{-2}$ and $\mathrm{Ca}_{c}=1.6 \times 10^{-2}$, and consequently, a distinct flow regime (a dripping regime) occurs where the emerging drop during the period of generation is unable to block the channel. In addition, the drop generations are much faster (Table II) and the ratio $(L / W)$ of drop length $(L)$ over channel width $(W)$ approaches 1 or may be smaller than 1 [seen as suspended drops; see Fig. 5(b)]. Other than $Q_{\mathrm{H}_{2} \mathrm{O} / L \mathrm{CO}_{2}}$ and $\mathrm{Ca}_{c}$, Table II also lists the periods $\left(t_{0}, \mathrm{~ms}\right)$ and the frequencies $\left[f=\left(1 / t_{0}\right), \mathrm{Hz}\right]$ of all the drop generations of the relevant cases. For case 1 to 21 , high frequencies $(>100 \mathrm{~Hz})$ are achieved in the vicinity of $Q_{\mathrm{H}_{2} \mathrm{O}} / Q_{L_{\mathrm{CO}_{2}}}=1$ (specifically, $Q_{\mathrm{H}_{2} \mathrm{O}} / Q_{L_{\mathrm{CO}}}=0.67$ to 1.86 ); for the cases with a constant liquid $\mathrm{CO}_{2}$ flow (case 22 to 28), the frequencies of drop generations are positively correlated with $\mathrm{Ca}_{c}$, and those of the two dripping regimes are so high that although a faster frame rate $(8000 \mathrm{fps}$, compared with $5000 \mathrm{fps}$ for cases 1 to 21 and $6000 \mathrm{fps}$ for cases 22 to 26) of the camera is applied, it does not improve much in providing quality captures of the drops, especially after the generation (Table II).

\section{LENGTH, AFTER-GENERATION SPEED, AND SPACING OF GENERATED LIQUID $\mathrm{CO}_{2}$ DROPS}

Our study has investigated the flow regimes (shown in Fig. 5) resulting from various flow rate ratios $\left(Q_{\mathrm{H}_{2} \mathrm{O}} / Q_{L \mathrm{CO}_{2}}\right)$ as well as $\mathrm{Ca}$ numbers of the continuous phase water. Within the ranges of these two dimensionless parameters, drop flows (including the dripping regime in case 27 and 28) and coflows are the two main flow regimes. Focusing on the drop flows, the length $(L)$ and speed $(V)$ of the generated liquid $\mathrm{CO}_{2}$ drops and the spacing $(S)$ between an emerging drop and the adjacent generated one during one period are measured, respectively.

\section{A. Drop length $(L / W)$ as a function of $Q_{\mathrm{H}_{2} \mathrm{O}} / Q_{L \mathrm{CO}_{2}}$}

Shown in Fig. 4, the length of the generated liquid $\mathrm{CO}_{2}$ drop is measured from the front end to the back end of the drop. For each drop flow case in Table II, the length measurement is performed over multiple drops, and the mean value $\overline{\mathrm{L}}$ calculated from the sample lengths $\left(L_{i}, i=1,2,3, \ldots, N\right)$ is considered as the drop length for this case:

$$
\bar{L}=\frac{1}{N} \sum_{i=1}^{N} L_{i},
$$

or

$$
\frac{\bar{L}}{W}=\frac{1}{N} \sum_{i=1}^{N}\left(\frac{L_{i}}{W}\right) .
$$

In addition, the standard deviation, $s$, is determined using Bessel's correction, which is written as

$$
s=\sqrt{\frac{1}{N-1} \sum_{i=1}^{N} \frac{\left(L_{i}-\bar{L}\right)^{2}}{W^{2}}} .
$$

Based on the above equations, the normalized liquid $\mathrm{CO}_{2}$ drop length $(L / W)$ is plotted against the flow rate ratio $\left(Q_{\mathrm{H}_{2} \mathrm{O}} / Q_{L \mathrm{CO}_{2}}\right)$ and is shown in Fig. 7. An error bar representing the standard deviation is also added. When the total flow rate of liquid $\mathrm{CO}_{2}$ and water is $100 \mu \mathrm{l} / \mathrm{min}$ [Fig. 7(a)], the length of the liquid $\mathrm{CO}_{2}$ drop decreases rapidly as $Q_{\mathrm{H}_{2} \mathrm{O}} / Q_{L \mathrm{CO}_{2}}$ rises from around 0.2 to 1 ; however, this decrease tends to reach a plateau as $Q_{\mathrm{H}_{2} \mathrm{O}} / Q_{L \mathrm{CO}_{2}}$ further increases from 1 up to 9 . When the flow rate of liquid $\mathrm{CO}_{2}$ is maintained as $50 \mu \mathrm{l} / \mathrm{min}$ [Fig. 7(b)], the variation of the drop length complying with the flow rate ratio is analogous to that in Fig. 7(a). Overall, the normalized liquid $\mathrm{CO}_{2}$ drop length $L / W$ versus the flow rate ratio $Q_{\mathrm{H}_{2} \mathrm{O}} / Q_{L \mathrm{CO}_{2}}$ can be approximated by a power function

$$
\frac{L}{W} \sim 1+A\left(Q_{\mathrm{H}_{2} \mathrm{O}} / Q_{L \mathrm{CO}_{2}}\right)^{B},
$$

where the exponent $B$ is negative $(B<0)$. Specifically, the fitted curves in Fig. 7(a) and 7(b) are formulated as $L / W=1+2.83\left(Q_{\mathrm{H}_{2} \mathrm{O}} / Q_{L \mathrm{CO}_{2}}\right)^{-0.768}$ and $L / W=1+$ $2.86\left(Q_{\mathrm{H}_{2} \mathrm{O}} / Q_{\mathrm{LCO}_{2}}\right)^{-1.274}$, respectively. These results are different from the long-held claim that the drop (or droplet) size is approximately linear with the flow rate ratio of the dispersed to the continuous phase $\left(Q_{\mathrm{LCO}_{2}} / Q_{\mathrm{H}_{2} \mathrm{O}}\right)$ at T-junctions under the squeezing (and/or transition) regime, where the factor $A$ is estimated as $d_{\text {neck }} / v_{\text {squeeze }}$, i.e., the time of the drop's neck 
(a)

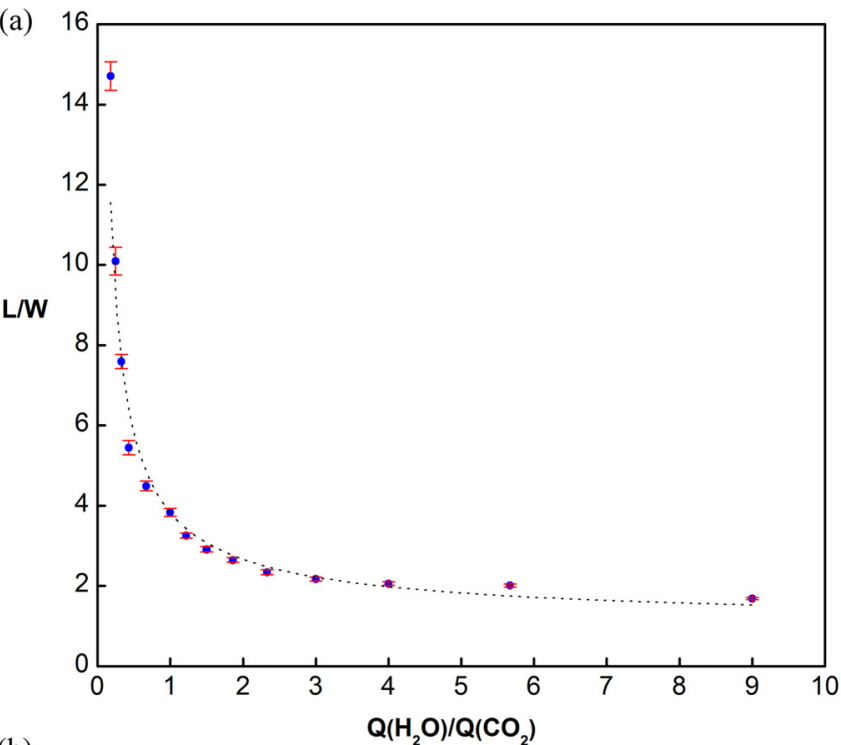

(b)

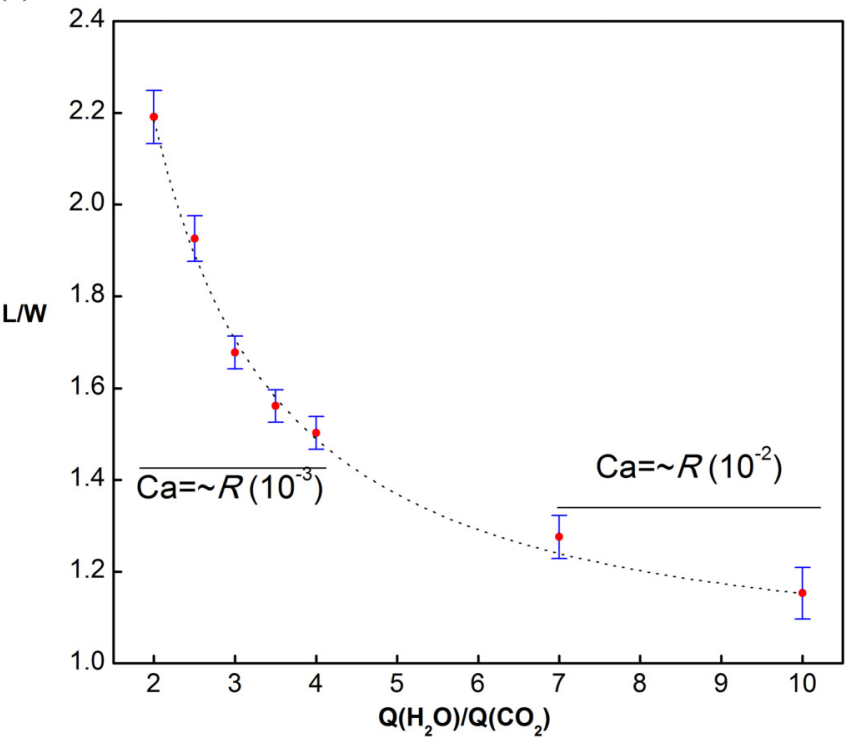

FIG. 7. Liquid $\mathrm{CO}_{2}$ drop size as a function of flow rate ratio $\left(Q_{\mathrm{H}_{2} \mathrm{O}} / Q_{L \mathrm{CO}_{2}}\right)$ : the drop length $(L)$ is normalized by the width $(W=$ $150 \mu \mathrm{m}$ ) of the microchannel. (a) The total flow rate of liquid $\mathrm{CO}_{2}$ and water is a constant $\left(Q_{\mathrm{H}_{2} \mathrm{O}}+Q_{\mathrm{LCO}_{2}}=100 \mu \mathrm{l} / \mathrm{min}\right)$; (b) the flow rate of liquid $\mathrm{CO}_{2}$ is a constant $\left(Q_{L \mathrm{CO}_{2}}=50 \mu \mathrm{l} / \mathrm{min}\right), \mathrm{Ca}_{c}$ steps towards $O\left(10^{-2}\right)$ from $O\left(10^{-3}\right)$ when $Q_{\mathrm{H}_{2} \mathrm{O}} / Q_{L \mathrm{CO}_{2}}$ reaches 7 . Error bar: the standard deviation $(s)$ of the mean normalized drop length $(\bar{L} / W)$.

being squeezed off [4]. It is noteworthy that, although an inverse flow rate ratio $\left(Q_{c} / Q_{d}\right.$ instead of $\left.Q_{d} / Q_{c}\right)$ is applied in our study, it does not alter the intention of correlating drop sizes to comparative flow rates. Although the exponent $B$ here does not agree with the prediction by Garstecki et al., it is still within the vicinity of $(-1)$. However, the determination of $A$ in our study requires taking account of not only the "squeezing" (i.e., truncating) time but also the "elongating" time (see Fig. 5) when the liquid $\mathrm{CO}_{2}$ keeps entering and thus increases the length of the emerging drop, which is attributed to the elongating-squeezing regime distinguished from the general "squeezing" regime.

\section{B. After-generation drop speeds under various $Q_{\mathrm{H}_{2} \mathrm{O}} / Q_{L \mathrm{CO}_{2}}$}

The methodology for obtaining the drop speed, $V$, after its generation has been briefly discussed in Fig. 4. More specifically, one liquid $\mathrm{CO}_{2}$ drop immediately after its generation starts to be identified, and its centroid can be located with the Matlab code. Based on the frame rate (fps) applied to imaging, the time interval, $\Delta t$, between two consecutive frames should be $1 /(\mathrm{fps}-1)$. Since very high frame rates $\left(\mathrm{fps} \sim 10^{3}\right)$ are used in our experiments, the time interval can be approximated as $\Delta t \approx 1 / \mathrm{fps}$. Moreover, the drop displacement (centroid to centroid), $\Delta d$, during this time interval can also be measured depending on the centroid location shift. Therefore, the speed $V_{i}$ of this specific drop from the $i$ th to the $(i+1)$-th frame can be calculated as

$$
V_{i}=\frac{\left.\Delta d\right|_{i \rightarrow(i+1)}}{1 / \mathrm{fps}} .
$$

Assume the $(N+1)$-th frame is the last one which still presents a complete profile of this drop within the field of view of this video, the mean speed can be calculated from

$$
V_{j}=\frac{1}{N} \sum_{i=1}^{N} V_{i}=\frac{1}{N} \sum_{i=1}^{N} \frac{\left.\Delta d\right|_{i \rightarrow(i+1)}}{1 / \mathrm{fps}},
$$

where $V_{j}$ is the speed of this drop, and $j$ denotes the $j$ th $(j=1,2,3, \ldots, M)$ liquid $\mathrm{CO}_{2}$ drop whose speed has been measured from the video. Accordingly, the drop speed as a characteristic speed of one-drop flow case (Table II) can be determined by

$$
\bar{V}=\frac{1}{\mathrm{M}} \sum_{j=1}^{\mathrm{M}} V_{j}
$$

Analogous to the drop length, the standard deviation of the drop speed for each drop flow case is also provided as

$$
s^{\prime}=\sqrt{\frac{1}{\mathrm{M}-1} \sum_{j=1}^{\mathrm{M}}\left(V_{j}-\bar{V}\right)^{2}} .
$$

Figure 8 plots the after-generation drop speed for all drop flow cases against their specific values of $Q_{\mathrm{H}_{2} \mathrm{O}} / Q_{\mathrm{LCO}_{2}}$ ranging from around 0.2 to 9 for $Q_{\mathrm{H}_{2} \mathrm{O}}+Q_{L_{\mathrm{CO}_{2}}}=100 \mu \mathrm{l} / \mathrm{min}$ [Fig. 8(a)] and from 2 to 10 for $Q_{L_{C O}}=50 \mu \mathrm{l} / \mathrm{min}$ [Fig. 8(b)], respectively.

In addition, three average velocities, i.e., $V_{\mathrm{H}_{2} \mathrm{O}, a}, V_{\mathrm{CO}_{2}, a}$, and $V_{\text {Total }, a}$, that are derived from the flow rates of water and liquid $\mathrm{CO}_{2}$ are introduced as the reference velocities. For the drop flows under a condition of $Q_{\mathrm{H}_{2} \mathrm{O}}+Q_{\mathrm{LCO}_{2}}=100 \mu \mathrm{l} / \mathrm{min}$ [Fig. 8(a)], there exists a waxing and waning relation between $V_{\mathrm{H}_{2} \mathrm{O}, a}$, and $V_{\mathrm{CO}_{2}, a}$ as $Q_{\mathrm{H}_{2} \mathrm{O}} / Q_{L_{\mathrm{CO}_{2}}}$ monotonically increases or decreases in the studied range; however, the hypothetical average velocity $V_{\text {Total, } a}$ derived from the total flow rates is a constant $(111 \mathrm{~mm} / \mathrm{s})$. Comparatively, the speed of the drop after generation is much closer to their corresponding $V_{\text {Total, } a}$ under the same $Q_{\mathrm{H}_{2} \mathrm{O}} / Q_{L \mathrm{CO}_{2}}$ for almost all drop flow cases; the only two exceptions are under the two extreme conditions of $Q_{\mathrm{H}_{2} \mathrm{O}} / Q_{L \mathrm{CO}_{2}}(0.18$ and 9$)$ when either liquid $\mathrm{CO}_{2}$ or water has dominated over the other resulting in the final drop speed. Overall, the drop speed values agree well with the averaged 
(a)

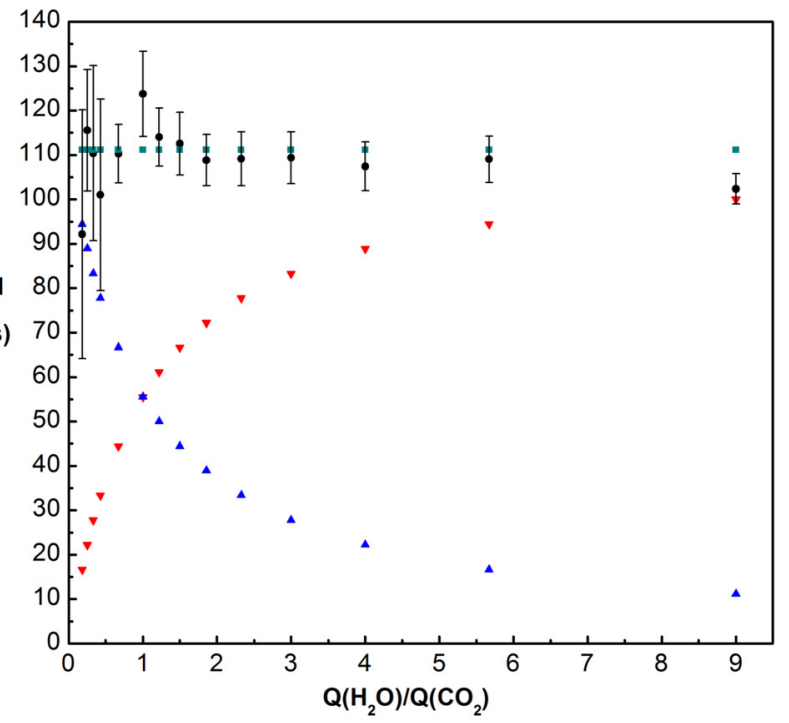

(b)

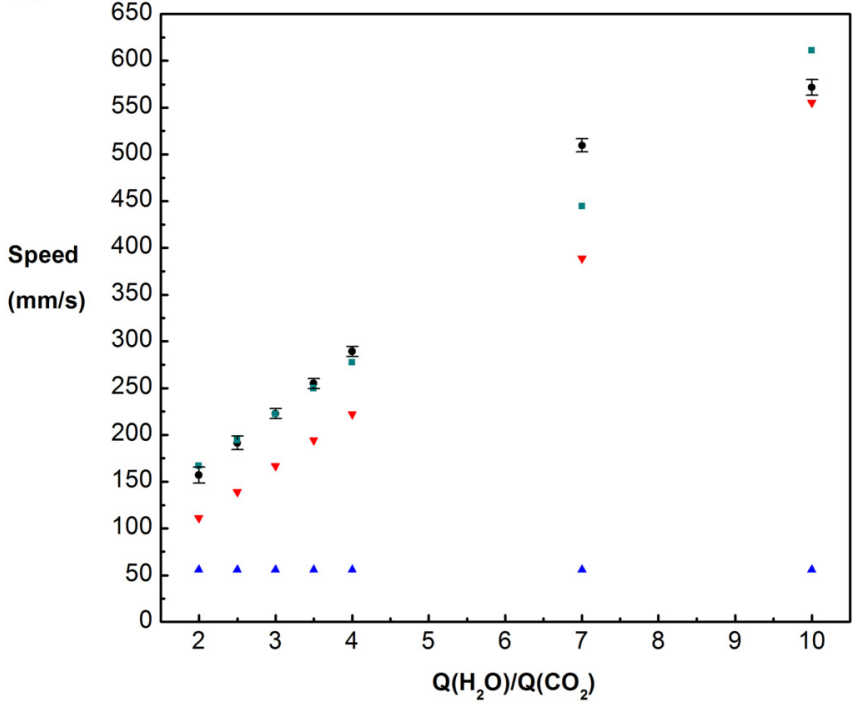

FIG. 8. Comparison of the speeds of the liquid $\mathrm{CO}_{2}$ drops $V_{\text {drop }}(-)$ after generation to the average flow velocities of water $V_{\mathrm{H}_{2} \mathrm{O}, a}(\boldsymbol{\nabla})$ and liquid $\mathrm{CO}_{2} V_{\mathrm{CO}_{2}, a}(\mathbf{\Delta})$ as well as the averaged total velocity $V_{\text {Total }, a}(\square)$ of the two fluids under drop flow cases for (a) $Q_{\mathrm{H}_{2} \mathrm{O}}+Q_{L_{\mathrm{CO}_{2}}}=100 \mu \mathrm{l} / \mathrm{min}$ and (b) $Q_{L_{\mathrm{CO}_{2}}}=50 \mu \mathrm{l} / \mathrm{min}$, respectively. Average velocities are defined as $V_{\mathrm{H}_{2} \mathrm{O}, a}=Q_{\mathrm{H}_{2} \mathrm{O}} /(D W)$, $V_{\mathrm{CO}_{2}, a}=Q_{\mathrm{CO}_{2}} /(D W)$ and $V_{\text {Total }, a}=\left(Q_{\mathrm{H}_{2} \mathrm{O}}+Q_{L_{\mathrm{CO}}}\right) /(D W)$. Error bar: the standard deviation $\left(s^{\prime}\right)$ of $V_{\text {Drop }}$.

total velocity $V_{\text {Total }, a}$ especially when $Q_{\mathrm{H}_{2} \mathrm{O}} / Q_{L_{\mathrm{CO}_{2}}}>1$; although there is less conformity when $Q_{\mathrm{H}_{2} \mathrm{O}} / Q_{L \mathrm{CO}_{2}} \leqslant 1, V_{\text {Drop }}$ are numerically proximal to $V_{\text {Total }, a}$ rather than $V_{\mathrm{H}_{2} \mathrm{O}, a}$ or $V_{\mathrm{CO}_{2}, a}$ particularly accounting for their error bars. For the drop flows under the condition $Q_{\mathrm{LCO}_{2}}=50 \mu \mathrm{l} / \mathrm{min}$ [Fig. 8(b)], $V_{\mathrm{CO}_{2}, a}$ becomes a constant $(55.6 \mathrm{~mm} / \mathrm{s})$ and the drop speed keeps increasing linearly as a result of the increasing $Q_{\mathrm{H}_{2} \mathrm{O}}$ from $100 \mu \mathrm{l} / \mathrm{min}$ to $200 \mu \mathrm{l} / \mathrm{min}$ per $25 \mu \mathrm{l} / \mathrm{min}$. Similar to that when $Q_{\mathrm{H}_{2} \mathrm{O}}+Q_{\mathrm{LCO}_{2}}=100 \mu \mathrm{l} / \mathrm{min}, V_{\text {Drop }}$ agrees very well with $V_{\text {Total }, a}$. However, as the flow rate of water strides to $350 \mu \mathrm{l} / \mathrm{min}$ and $500 \mu \mathrm{l} / \mathrm{min}$ [accordingly, $\mathrm{Ca}_{c}$ increases to $O\left(10^{-2}\right)$ from $O\left(10^{-3}\right)$ ], the dripping regime of drop generation emerges where the emerging drop can never touch the far-end channel wall and the period of generation is extremely short $\left(t_{0}<2 \mathrm{~ms}\right)$. By observing the drop generations within case 27, we believe that at the very end of the generation the tip of the emerging drop has a speed $\left(V_{\mathrm{CO}_{2}, a}^{\prime}\right)$ faster than that inherits from the flow of liquid $\mathrm{CO}_{2}$ through the entire cross section of the channel, which may be due to the actually narrowed cross section [case 27 in Fig. 5(b)] for the same flow rate $Q_{\mathrm{LCO}_{2}}$. Thus, a revised $V_{\text {Total }, a}^{\prime}$ instead of the one in Fig. 8(b) needs to be used for comparison, which can be formulated as

$$
V_{\mathrm{Total}, a}^{\prime}=\frac{Q_{\mathrm{H}_{2} \mathrm{O}}}{D W}+\frac{Q_{\mathrm{CO}_{2}}}{D(b W)}
$$

in which the second term on the right-hand side is $V_{\mathrm{CO}_{2}, a}^{\prime}$,

$$
V_{\mathrm{CO}_{2}, a}^{\prime}=\frac{Q_{\mathrm{CO}_{2}}}{D(b W)}
$$

where factor $b$ in denominator is smaller than 1 and $b W$ indicates the actual channel width occupied by the liquid $\mathrm{CO}_{2}$ in the T-junction region but below its corner. Note that $b W$ ought to be location-dependent along the interface; however, for simplification an estimated median value $(a \sim 1 / 2)$ will be employed. Based on the above assumption, we have

$$
V_{\text {Total }, a}^{\prime}-V_{\text {Total }, a}=\frac{1-b}{b} \frac{Q_{\mathrm{CO}_{2}}}{D W},
$$

Substituting $b \quad(\sim 1 / 2) \quad$ into $\quad$ Eq. (11) yields $\left(V_{\text {Total }, a}^{\prime}-V_{\text {Total }, a}\right)=Q_{\mathrm{CO}_{2}} /(D W), \quad$ i.e., $\quad V_{\text {Total }, a}^{\prime}=$ $V_{\text {Total }, a}+V_{\mathrm{CO}_{2}, a}$. When $Q_{\mathrm{H}_{2} \mathrm{O}} / Q_{L_{\mathrm{CO}_{2}}}=7 \quad$ [Fig. $\left.8(\mathrm{~b})\right]$, $V_{\text {Drop }}$ is measured as $509.7 \mathrm{~mm} / \mathrm{s}$, and $V_{\text {Total }, a}$ is $444.4 \mathrm{~mm} / \mathrm{s}$; if the revised averaged total velocity $V_{\text {Total }, a}^{\prime}(500 \mathrm{~mm} / \mathrm{s})$ is used to compare with $V_{\text {Drop }}$, it still justifies that $V_{\text {Drop }}$ correlates with the averaged total velocity. As $Q_{\mathrm{H}_{2} \mathrm{O}} / Q_{L \mathrm{CO}_{2}}$ reaches $10, Q_{\mathrm{H}_{2} \mathrm{O}}$ becomes a dominant role in determining the final drop speed; even without accounting for the difference of the averaged total velocity caused by the liquid $\mathrm{CO}_{2}$, the estimation of $V_{\text {Drop }}$ using $V_{\text {Total, } a}$ can still be of a $93 \%$ confidence, which is calculated as

$$
\begin{aligned}
\left(1-\frac{V_{\text {Total }, a}-V_{\text {Drop }}}{V_{\text {Drop }}}\right) \% & =\left(1-\frac{\frac{611.1 \mathrm{~mm}}{s}-\frac{571.9 \mathrm{~mm}}{\mathrm{~s}}}{\frac{571.9 \mathrm{~mm}}{\mathrm{~s}}}\right) \% \\
& \approx 93 \% .
\end{aligned}
$$

\section{Periodic development of spacing $S$ between an emerging drop and the adjacent formed one}

Spacing between two consecutive drops in the flow channel represents how closely the chasing drop follows with the preceding one. This resulted spacing actually originates from that between the emerging drop and the adjacent alreadyformed drop at the very end of one period of drop generation as well as its development during the period. Different from the drop length and the drop speed as characteristic parameters of the formed drop, the spacing between the emerging drop and the formed one correlates the two drops and is time-dependent within one period. The periodic spacing development can be analyzed by taking advantage of the drop length increase during the filling stage and the speed of the emerging drop and the formed one as discussed above. The spacing always evolves from an initial value of $S_{0}$ that stems from the pinch-off and the retractions at the interface for producing the 
(a)
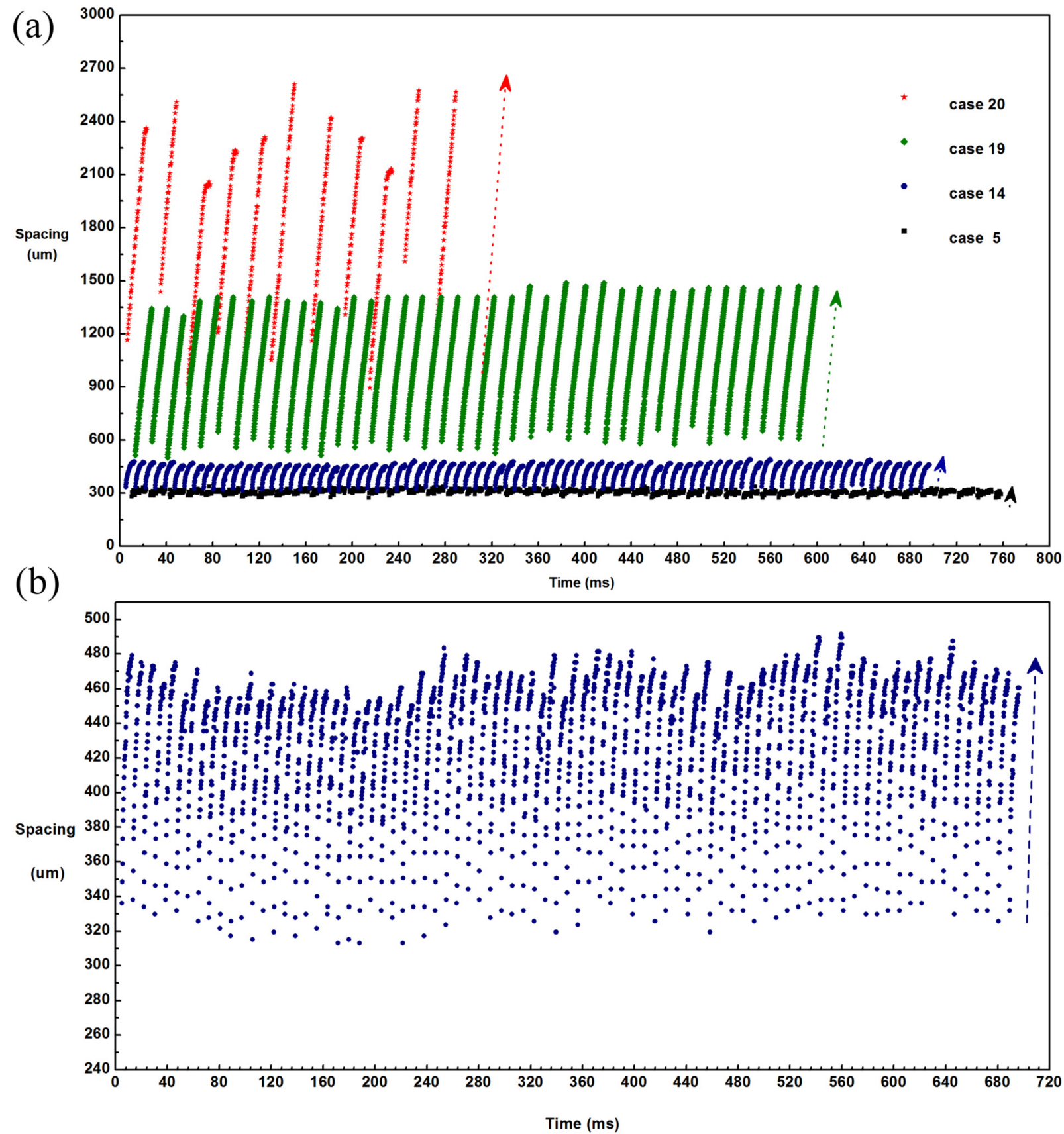

FIG. 9. The development of spacing between the emerging drop and the adjacent formed one: (a) as observed under the drop flow case 5 $(\bullet)$, case $14(\bullet)$, case $19(\diamond)$ and case $20(\star)$, respectively; (b) the detailed spacing development observed continuously from 86 pairs of those two drops under case $14\left(Q_{\mathrm{H}_{2} \mathrm{O}}=55 \mu \mathrm{l} / \mathrm{min}\right.$ and $\left.Q_{\mathrm{CO}_{2}}=45 \mu \mathrm{l} / \mathrm{min}\right)$. Each upright line (indicated by the arrow) in the same row depicts an elemental spacing development during one period of the (emerging) drop generation.

formed liquid $\mathrm{CO}_{2}$ drop. The spacing development between emerging drops and their adjacent already formed ones have been investigated through imaging almost all the drop flow cases except case 21 in our experiments; the exception of case 21 is due to that the resulted spacing therein has been extremely long that it is beyond the maximum observable field of view. Figure 9(a) shows the spacing development between emerging drops and their adjacent already formed ones as observed under the drop flow case 5, case 14, case 19, and case 20, respectively; Fig. 9(b) focuses on drop flow case 14 and shows more details on the spacing increases within one period of the drop generation. For case $5\left(Q_{\mathrm{H}_{2} \mathrm{O}}=20 \mu \mathrm{l} / \mathrm{min}\right.$ and $\left.Q_{\mathrm{CO}_{2}}=80 \mu \mathrm{l} / \mathrm{min}\right), t_{s f}, t_{e s}$, and $t_{t r}$ comprising one period of drop generation are around $1.3,13.6$, and $2 \mathrm{~ms}$, respectively. As a result, $W / t_{s f}$ becomes equivalent to $\left(Q_{\mathrm{H}_{2} \mathrm{O}}+Q_{L \mathrm{CO}_{2}}\right) /(D W)$ numerically during the stagnating and filling stage. It is also observed that the emerging drop moves approximately at a speed of $Q_{L_{C O}} /(D W)$ within $\left(t_{e s}+t_{t r}\right)$, which is close to the after-generation speed of the formed one. Therefore, the spacing during the overall period roughly becomes a constant that is estimated by $S_{0}$. This result is verified by experimental measurements [i.e., case 5 in Fig. 9(a)] where the spacing is 


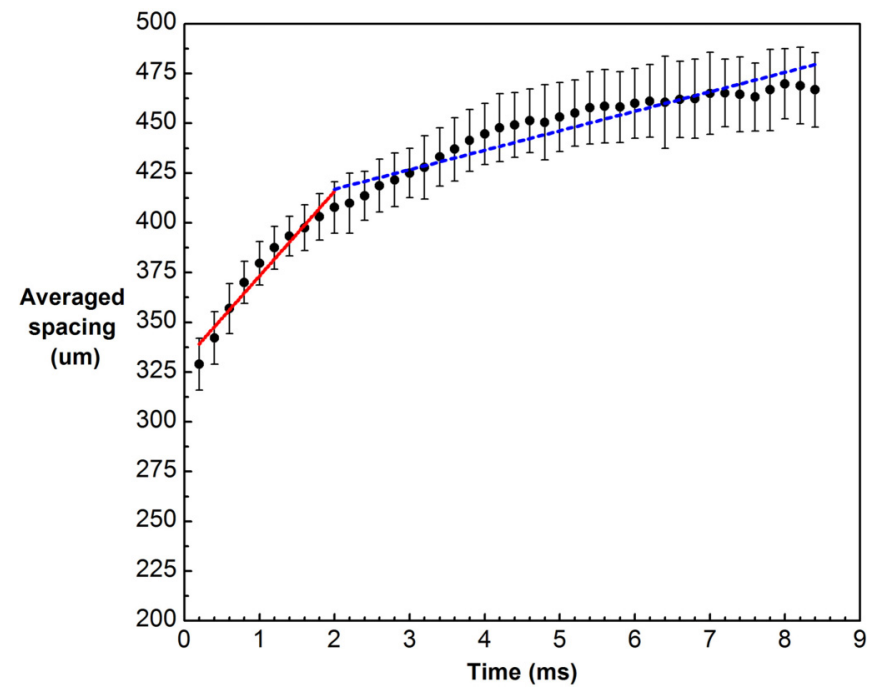

FIG. 10. Averaged spacing within one period $(8.4 \mathrm{~ms})$ of drop generation under drop flow case 14 . The experimental data herein are averaged from those in Fig. 9(b), and each error bar indicates two standard deviations from the averaged spacing upon the corresponding time moment. Dashed lines are the fitting lines from the averaged spacing.

(307.2 \pm 11.2$)$ um. For cases 14 and 19, within one period of drop generation, it is clear that the spacing increases with time; however, the increasing rates slow during the later stages, as shown by the slopes. This can be interpreted from the speed differences during $t_{s f}$ and $\left(t_{e s}+t_{t r}\right)$. And the difference is generally larger during $t_{s f}$ than that during $\left(t_{e s}+t_{t r}\right)$, provided that both cases are featured with a higher flow rate of water which narrows the speed difference between two drops during $\left(t_{e s}+t_{t r}\right)$. Thus the spacing increasing rates are decelerated. However, the experimental data of spacing for case 20 among different periods, or say, different pairs of those two drops are not so uniform as that for other cases, though the spacing development within one specific period is still mostly linear. It is believed that the overall oscillating spacing under case 20 is resulted from the very low flow rate of liquid $\mathrm{CO}_{2}\left(Q_{\mathrm{CO}_{2}}=15 \mu \mathrm{l} / \mathrm{min}\right.$ which might not be very reliable as provided by the pump.) as well as the resulting high $Q_{\mathrm{H}_{2} \mathrm{O}} / Q_{\mathrm{CO}_{2}}$; moreover, a $5 \times$ objective instead of $10 \times$ is applied for imaging the long spacing under case 20, which compromises the resolution of the video and induces more errors into the spacing measurements.

The upright dot lines plotted in Fig. 9(b) show the details of the spacing increases of 86 consecutive pairs of the emerging drops and their adjacent already formed counterparts over a total time of almost $700 \mathrm{~ms}$, and one period of the drop generation is $t_{0}=8.4 \mathrm{~ms}\left[t_{s f}=2 \mathrm{~ms}\right.$ and $\left.\left(t_{e s}+t_{t r}\right)=6.4 \mathrm{~ms}\right]$. The spacing data of the 86 pairs, as a sample of case 14 , are averaged at each moment within the one period, $t_{0}$, per $0.2 \mathrm{~ms}$ time interval derived from $t_{0}=1 / f=1 / 5000$ to reflect the characteristic spacing development of this drop flow case. This averaging treatment seems as a horizontal squeezing of the sponge-like data shown in Fig. 9(b) into one single upright line. The averaged spacing within one period of drop generation are plotted (as the black dots) in Fig. 10, and the error bar indicates a $95 \%$ confidence of the spacing within two standard deviations from the mean value (shown by the dot) based on the normal distribution. The experimental spacing versus time, within one period, $t_{0}$, can be linearly fitted as

$$
\begin{aligned}
\operatorname{spacing}_{\mathrm{ex}, \mathrm{fit}}(\mu \mathrm{m}) & =330.73+42.55 t, \quad 0<t \leqslant 2 \mathrm{~ms}(13 \mathrm{a}) \\
& =397.35+9.78 t, \quad 2<t \leqslant 8.4 \mathrm{~ms} .
\end{aligned}
$$

The total sum of squares (TSS) and the residual sum of squares $(R S S)$ for the above two fitting functions are $41.25 \mu \mathrm{m}^{2}$ and $2.3 \mu \mathrm{m}^{2}$ within $0-2 \mathrm{~ms}$ and $48.93 \mu \mathrm{m}^{2}$ and $4.95 \mu \mathrm{m}^{2}$ within 2-8.4 ms, respectively. Instead of $R^{2}$ as the coefficient of determination, adjusted $R^{2}$ is introduced below to weigh how well the fittings are relative to the experimental spacing:

$$
\text { adjusted } R^{2}=1-\frac{R S S /(n-K-1)}{T S S /(n-1)},
$$

where $n$ and $K$ are the number of points and the number of explanatory variables, respectively. Here $n$ for the two functions are 10 and 33 , and $K$ is 1 for both functions since there is only one variable time $(t)$ in the question. Thus, adjusted $R^{2}$ for the two fitting functions can be calculated as $93.72 \%$ and $89.56 \%$.

Revealed by the fittings [see Eq. (13)], the spacing starts from an initial value $S_{0}$ (i.e., the $y$-intercept in Fig. 10) that stems from the pinch-off and the retractions at the interface during the drop generation and increases linearly within both the stagnating and filling stage and the elongating and squeezing stage based on the respective drop speed differences. Moreover, the increasing rate in the latter stage is slower than that in the former stage since the speed of the emerging drop is more dominated by the continuous fluid that results in a smaller speed difference as well.

\section{CONCLUSION}

In this first part of our study on a pair of highly pressurized partially immiscible fluids (liquid $\mathrm{CO}_{2}$ and water are used as the dispersed and the continuous phase, respectively) confined in a micro-T-junction, we focus on the experimental results and analyses. Over the range of flow conditions investigated in our study [Ca $\sim O\left(10^{-4}\right)$ to $O\left(10^{-2}\right)$ and $\left(Q_{\mathrm{H}_{2} \mathrm{O}} / Q_{L \mathrm{CO}_{2}}\right) \sim 5 / 95$ to $90 / 10$ for a constant total flow rate and $100 / 50$ to $500 / 50$ for a constant flow rate of the dispersed phase, respectively], two main flow patterns have been identified: drop flow [Ca $~$ $O\left(10^{-3}\right)$ to $\left.O\left(10^{-2}\right)\right]$ and coflow $\left[\mathrm{Ca} \sim\left(10^{-4}\right)\right]$; the drop flow is characterized by an elongating-squeezing regime in which the dispersed liquid $\mathrm{CO}_{2}$ first fills the main channel and the continuous phase (water) then squeezes the dispersed stream and simultaneously elongates it; as a result, the common "necking" time for the truncation is increased (both squeezing and elongating contribute to this) and the truncation point is shifted further downstream from around the corner of the T-junction. This effect explains the role of the factor $\alpha$ in the formulation $L / W=1+\alpha(Q c / Q d)^{-1}$ and accounts for the $\alpha$ (much larger than 1 ) in our cases. A transitional capillary number of $1 \times 10^{-2}$ is also characterized in our study as the dripping regime emerges. The interface of the emerging drop in 
the dripping regime can never touch the far-end channel wall, and the drop generation is characterized by drop generation frequencies $(f \geqslant 600 \mathrm{~Hz})$ and smaller drops $\left(L_{\text {drop }}<W\right)$.

In addition, we have measured the after-generation speeds of the drops, which indicates the rapidness of the newly produced drop flows downstream from the T-junction. Generally, this transient speed can be approximated to the averaged value from the total flow rates of the two fluids divided by the cross-sectional area of the main channel.

Although only the experimental data and comparisons to the calculated values based on flow rates have been reported in this work, these (together with the approximations) might be comprehended by the (impulse-) momentum theorem during the truncating stage of the drop generation. On the interface in the truncation region there is a net impulse towards downstream which increases the momentum to the to-be-generated drop as well as its speed. The development of drop spacing within one period of the drop generation as well as the final spacing values at the end of the one period are reported here. The spacing always starts from an initial value
$S_{0}$ and linearly increases during stages, though the increasing rates vary due to narrowed drop speed difference. In the second part of this study, we provide theoretical justifications to the current quantitative characterizations on the drop flow, and two mathematical models are developed for predicting the drop length and the drop spacing.

\section{ACKNOWLEDGMENTS}

N.Q. gratefully acknowledges the financial support from the China Scholarship Council (CSC) under File No. 201204910160. The authors acknowledge the Carbon Management Canada (Theme C: Secure Carbon Storage, Project C393) and the Networks of Centres of Excellence (NCE) of Canada for research grants and David Wong's assistance with the Matlab codes. The microfluidic chip was fabricated at the Toronto Nanofabrication Centre at the University of Toronto, and the microfluidic connector was machined at the University of Waterloo.
[1] P. J. A. Kenis, R. F. Ismagilov, and G. M. Whitesides, Science 285, 83 (1999).

[2] T. Thorsen, R. W. Roberts, F. H. Arnold, and S. R. Quake, Phys. Rev. Lett. 86, 4163 (2001).

[3] P. Garstecki, M. J. Fuerstman, and G. M. Whitesides, Phys. Rev. Lett. 94, 234502 (2005)

[4] P. Garstecki, M. J. Fuerstman, H. A. Stone, and G. M. Whitesides, Lab. Chip. 6, 437 (2006).

[5] M. De Menech, P. Garstecki, F. Jousse, and H. A. Stone, J. Fluid Mech. 595, 141 (2008)

[6] H. A. Stone, A. D. Stroock, and A. Ajdari, Annu. Rev. Fluid Mech. 36, 381 (2004).

[7] T. M. Squires and S. R. Quake, Rev. Mod. Phys. 77, 977 (2005).

[8] A. Gunther and K. F. Jensen, Lab. Chip. 6, 1487 (2006).

[9] A. M. Gañán-Calvo and J. M. Gordillo, Phys. Rev. Lett. 87, 274501 (2001).

[10] R. Dreyfus, P. Tabeling, and H. Willaime, Phys. Rev. Lett. 90, 144505 (2003).

[11] S. van der Graaf, T. Nisisako, C. G. P. H. Schroen, R. G. M. van der Sman, and R. M. Boom, Langmuir 22, 4144 (2006).

[12] V. van Steijn, M. T. Kreutzer, and C. R. Kleijn, Chem. Eng. Sci. 62, 7505 (2007).

[13] A. M. Leshansky and L. M. Pismen, Phys. Fluids 21, 023303 (2009).

[14] V. van Steijn, C. R. Kleijn, and M. T. Kreutzer, Phys. Rev. Lett. 103, 214501 (2009).

[15] T. T. Fu, Y. G. Ma, D. Funfschilling, C. Y. Zhu, and H. Z. Li, Chem. Eng. Sci. 65, 3739 (2010).

[16] W. van Hoeve, B. Dollet, M. Versluis, and D. Lohse, Phys. Fluids 23, 092001 (2011).

[17] D. A. Hoang, L. M. Portela, C. R. Kleijn, M. T. Kreutzer, and V. van Steijn, J. Fluid Mech. 717, R4 (2013).

[18] J. D. Tice, A. D. Lyon, and R. F. Ismagilov, Anal. Chim. Acta. 507, 73 (2004).

[19] P. Guillot and A. Colin, Phys. Rev. E 72, 066301 (2005).
[20] G. F. Christopher, N. N. Noharuddin, J. A. Taylor, and S. L. Anna, Phys. Rev. E 78, 036317 (2008).

[21] J. H. Xu, S. W. Li, J. Tan, and G. S. Luo, Microfluid. Nanofluid. 5, 711 (2008).

[22] T. Cubaud and T. G. Mason, Phys. Fluids 20, 053302 (2008).

[23] J. D. Tice, H. Song, A. D. Lyon, and R. F. Ismagilov, Langmuir 19, 9127 (2003).

[24] T. Cubaud, M. Tatineni, X. L. Zhong, and C. M. Ho, Phys. Rev. E 72, 037302 (2005).

[25] N. Dietrich, S. Poncin, N. Midoux, and H. Z. Li, Langmuir 24, 13904 (2008)

[26] J. Tan, S. W. Li, K. Wang, and G. S. Luo, Chem. Eng. J. 146, 428 (2009).

[27] V. van Steijn, C. R. Kleijn, and M. T. Kreutzer, Lab. Chip. 10, 2513 (2010).

[28] J. Atencia and D. J. Beebe, Nature (London) 437, 648 (2005).

[29] G. F. Christopher and S. L. Anna, J. Phys. D Appl. Phys. 40, R319 (2007).

[30] R. Seemann, M. Brinkmann, T. Pfohl, and S. Herminghaus, Rep. Prog. Phys. 75, 016601 (2012).

[31] G. I. Taylor, Proc. R. Soc. London 146, 501 (1934).

[32] J. H. Xu, G. S. Luo, G. G. Chen, and J. D. Wang, J. Membrane Sci. 266, 121 (2005).

[33] J. Husny and J. J. Cooper-White, J. Non-Newton. Fluid 137, 121 (2006).

[34] L. Sang, Y. P. Hong, and F. J. Wang, Microfluid. Nanofluid. 6, 621 (2009).

[35] R. Abate, P. Mary, V. van Steijn, and D. A. Weitz, Lab. Chip. 12, 1516 (2012).

[36] H. H. Liu and Y. H. Zhang, J. Appl. Phys. 106, 034906 (2009).

[37] S. L. Anna, Annu. Rev. Fluid Mech. 48, 285 (2016).

[38] T. Glawdel, C. Elbuken, and C. L. Ren, Phys. Rev. E 85, 016322 (2012).

[39] D. Gobby, P. Angeli, and A. Gavriilidis, J. Micromech. Microeng. 11, 126 (2001). 
[40] B. S. Akpa, S. M. Matthews, A. J. Sederman, K. Yunus, A. C. Fisher, M. L. Johns, and L. F. Gladden, Anal. Chem. 79, 6128 (2007).

[41] H. Dogan, S. Nas, and M. Muradoglu, Int. J. Multiphas. Flow 35, 1149 (2009).

[42] S. K. Y. Tang, R. Derda, Q. M. Quan, M. Loncar, and G. M. Whitesides, Opt. Express 19, 2204 (2011).

[43] T. Cubaud and S. Notaro, Phys. Fluids 26, 122005 (2014).

[44] P. Nguyen, D. Mohaddes, J. Riordon, H. Fadaei, P. Lele, and D. Sinton, Anal. Chem. 87, 3160 (2015).

[45] J. J. Carroll, J. D. Slupsky, and A. E. Mather, J. Phys. Chem. Ref. Data 20, 1201 (1991).

[46] R. Logan, J. Chem. Educ. 75, 339 (1998).

[47] N. Spycher, K. Pruess, and J. Ennis-King, Geochim. Cosmochim. Ac. 67, 3015 (2003).

[48] L. W. Diamond and N. N. Akinfiev, Fluid Phase Equilibr. 208, 265 (2003).

[49] S. B. Wang and A. F. Clarens, Water Resour. Res. 48, W08518 (2012).

[50] D. M. Anderson, G. B. McFadden, and A. A. Wheeler, Annu. Rev. Fluid Mech. 30, 139 (1998).

[51] J. Kobayashi, Y. Mori, and S. Kobayashi, Chem. Commun. 20, 2567 (2005).

[52] F. Benito-Lopez, R. M. Tiggelaar, K. Salbut, J. Huskens, R. J. M. Egberink, D. N. Reinhoudt, H. J. G. E. Gardeniers, and W. Verboom, Lab. Chip. 7, 1345 (2007).

[53] F. Trachsel, B. Tidona, S. Desportes, and P. R. von Rohr, J. Supercrit. Fluid 48, 146 (2009).

[54] S. K. Luther and A. Braeuer, J. Supercrit. Fluids 65, 78 (2012).

[55] N. Assmann, S. Kaiser, and P. R. von Rohr, J. Supercrit. Fluid 67, 149 (2012).

[56] N. Assmann, H. Werhan, A. Ładosz, and P. Rudolf von Rohr, Chem. Eng. Sci. 99, 177 (2013).

[57] E. Tumarkin, Z. H. Nie, J. I. Park, M. Abolhasani, J. Greener, B. Sherwood-Lollar, A. Gunther, and E. Kumacheva, Lab. Chip. 11, 3545 (2011).

[58] M. Abolhasani, M. Singh, E. Kumacheva, and A. Gunther, Lab. Chip. 12, 1611 (2012).

[59] N. Liu, C. Aymonier, C. Lecoutre, Y. Garrabos, and S. Marre, Chem. Phys. Lett. 551, 139 (2012).

[60] T. Cubaud, M. Sauzade, and R. P. Sun, Biomicrofluidics 6, 022002 (2012).

[61] H. Fadaei, B. Scarff, and D. Sinton, Energ. Fuel. 25, 4829 (2011).

[62] A. Sell, H. Fadaei, M. Kim, and D. Sinton, Environ. Sci. Technol. 47, 71 (2013).
[63] S. Marre, C. Aymonier, P. Subra, and E. Mignard, Appl. Phys. Lett. 95, 134105 (2009).

[64] T. Gendrineau, S. Marre, M. Vaultier, M. Pucheault, and C. Aymonier, Angew. Chem. Int. Edit. 51, 8525 (2012).

[65] S. Marre, J. Baek, J. Park, M. G. Bawendi, and K. F. Jensen, JALA-J. Assoc. Lab. Aut. 14, 367 (2009).

[66] A. Ohashi, M. Sugaya, and H. B. Kim, Anal. Sci. 27, 567 (2011).

[67] R. Blanch-Ojea, R. M. Tiggelaar, J. Pallares, F. X. Grau, and J. G. E. Gardeniers, Microfluid. Nanofluid. 12, 927 (2012).

[68] R. Guillaument, A. Erriguible, C. Aymonier, S. Marre, and P. Subra-Paternault, J. Supercrit. Fluids 81, 15 (2013).

[69] S. K. Luther, J. J. Schuster, A. Leipertz, and A. Braeuer, J. Supercrit. Fluids 84, 121 (2013).

[70] S. Ogden, R. Boden, M. Do-Quang, Z. G. Wu, G. Amberg, and K. Hjort, Microfluid. Nanofluid. 17, 1105 (2014).

[71] S. Knaust, M. Andersson, K. Hjort, and L. Klintberg, J. Supercrit. Fluid. 107, 649 (2016).

[72] C. Y. Zhang, M. Oostrom, J. W. Grate, T. W. Wietsma, and M. G. Warner, Environ. Sci. Technol. 45, 7581 (2011).

[73] Y. Kim, J. M. Wan, T. J. Kneafsey, and T. K. Tokunaga, Environ. Sci. Technol. 46, 4228 (2012).

[74] Y. Wang, C. Y. Zhang, N. Wei, M. Oostrom, T. W. Wietsma, X. C. Li, and A. Bonneville, Environ. Sci. Technol. 47, 212 (2013).

[75] M. Kim, A. Sell, and D. Sinton, Lab. Chip. 13, 2508 (2013).

[76] F. Kazemifar, G. Blois, D. C. Kyritsis, and K. T. Christensen, Water Resour. Res. 51, 3017 (2015).

[77] S. Marre, Y. Roig, and C. Aymonier, J. Supercrit. Fluids 66, 251 (2012).

[78] M. Abolhasani, A. Gunther, and E. Kumacheva, Angew. Chem. Int. Ed. 53, 7992 (2014).

[79] S. Marre, A. Adamo, S. Basak, C. Aymonier, and K. F. Jensen, Ind. Eng. Chem. Res. 49, 11310 (2010).

[80] F. Laermer and A. Schilp, U.S. Patent No. 5,501,893, U.S. Patent and Trademark Office, 1996.

[81] See Supplemental Material at http://link.aps.org/supplemental/ 10.1103/PhysRevE.95.043110 for overviews of the three stages of one drop generation period for case 5 and case 21 .

[82] Edited by D. R. Lide, CRC Handbook of Chemistry and Physics (CRC Press, Boca Raton, FL, 2005).

[83] A. Hebach, A. Oberhof, N. Dahmen, A. Kogel, H. Ederer, and E. Dinjus, J. Chem. Eng. Data 47, 1540 (2002).

[84] A. Georgiadis, G. Maitland, J. P. M. Trusler, and A. Bismarck, J. Chem. Eng. Data 55, 4168 (2010).

[85] M. Zagnoni, J. Anderson, and J. M. Cooper, Langmuir 26, 9416 (2010). 